"This is the peer reviewed version of the following article: Catalytic Enantioselective Flow Processes with Solid-Supported Chiral Catalysts, which has been published in final form at https://doi.org/10.1002/tcr.201800097. This article may be used for non-commercial purposes in accordance with Wiley Terms and Conditions for Self-Archiving http://olabout.wiley.com/WileyCDA/Section/id-820227.html ".

\title{
Catalytic Enantioselective Flow Processes with Solid-Supported Chiral Catalysts
}

\author{
Carles Rodríguez-Escrich*[a] and Miquel A. Pericàs*[a],[b]
}

\begin{abstract}
Sustainability concerns are the wind in the sails for the development of novel, more selective catalytic processes. Hence, chiral catalysts play a crucial role in the green production of enantioenriched compounds. To further increase the green profile of this approach, the use of solid-supported catalytic species is appealing due to the reduced generation of waste, as well as the possibility of reusing the precious catalyst. Even more attractive is the implementation of flow processes based on these immobilized catalysts, a flexible strategy that allows to generate from milli- to multi-gram amounts of chiral product with a reduced footprint set-up. Herein, we will present the efforts devoted in our laboratory towards the immobilization of chiral catalysts and their use in single-pass, highly enantioselective, flow processes. Proline, diarylprolinols, other aminocatalysts, squaramides, thioureas, phosphoric acids and even chiral ligands and metalbased catalysts constitute our current toolkit of supported species for enantioselective catalysis.
\end{abstract}

\section{Introduction}

Sustainability is a transversal concept that stems from the notion that resources are finite and the human footprint in the planet has to be as faint as possible. ${ }^{[1]}$ Albeit it was industrial development that generated the current scenario, we must be aware that technological solutions represent the best way out of this spiraling situation. Countless initiatives are proposing ways to minimize the impact of human activity over Nature. Chemistry, despite its perceived association with pollution and poisoning of natural resources, is undoubtedly going to play a key role in fighting climate change and preserving the environment. The big question that arises is: how do we revert this situation in a global context that involves a growing demand of fine chemicals for technical, agricultural or health-related applications? Our dependence on the end-products of the chemical industry is more important than society thinks, so the solution has to come from changing the way these are produced. Sustainable chemistry is the attempt to adapt

[a] Dr. Carles Rodríguez-Escrich, Prof. Dr. Miquel A. Pericàs. Institute of Chemical Research of Catalonia (ICIQ)

The Barcelona Institute of Science and Technology (BIST) Avinguda Països Catalans 16, 43007, Tarragona (Spain) Fax: (+34) 977-920-243

E-mail: mapericas@iciq.es

[b] Prof. Dr. Miquel A. Pericàs, Departament de Química Orgànica, Universitat de Barcelona, 08080 Barcelona (Spain) the chemical practice to this idea. The answer to such a complex, multi-faceted problem cannot be a straightforward one; along these lines, Anastas and Warner introduced the 12 principles of Green Chemistry, ${ }^{[2]}$ a set of basic guidelines to light the way for a sustainable evolution of chemical practice.

The implementation of catalytic processes usually allows working under mild reaction conditions, using less elaborated materials and generating less waste. Consequently, it is perfectly aligned with many of the above-mentioned 12 principles. The demand of enantiopure compounds is also growing as a consequence of their use in advanced materials and the increasingly restrictive pharmaceutical regulations. ${ }^{[3]}$ In this scenario, the advantages of developing new catalytic enantioselective transformations ${ }^{[4]}$ become more evident, as the alternatives are hampered by substrate availability (chiral pool approach) or excessive substrate specificity (biocatalysis). The most important drawback of asymmetric catalysis is perhaps the cost of the chiral species required, which is one of the main bottlenecks for its full deployment in industrial environments. Upon immobilization, chiral catalysts can be easily recovered after the reaction is complete, which opens the possibility of reusing them. The efficiency of this approach is therefore subject to the robustness of the catalytically active species: the less off-cycle reactions that can kill the catalyst, the more advantageous this immobilization approach will be. ${ }^{[5]}$ The classical way to reuse these solidsupported catalysts has been lately challenged by an alternative method: the use of flow techniques to carry out what is nothing more than an in-line recycling. ${ }^{[6]}$ The benefits associated to this change of regime may be less than obvious to those not familiar with the field. However, the implementation of flow processes with immobilized catalysts entails savings in terms of solvent required to separate the catalyst, the direct translation of reaction conditions for the scale up and the possibility to produce big amounts of product with a reduced reactor volume. In two words, the process intensification ${ }^{[7]}$ inherent to this approach makes it a fundamental asset of green chemistry. In this context, it is important to mention that a recent report by the US Government Accountability Office (GAO) concluded that three categories of technology can make chemical production more sustainable: ${ }^{[8]}$ catalysts, which reduce the energy needed for chemical processes; solvents that are derived from renewable materials or are less hazardous than those currently employed; and continuous processing rather than batch processing. 
The design of a suitable immobilization strategy is crucial to obtain a heterogenized catalyst that replicates the behavior of its homogeneous counterpart. In this regard, two premises are to be considered for an optimal outcome: (a) ensuring enough distance between the active site and the solid support and (b) choosing a support material, a linker and a spacer that do not interfere with the catalytic process. A few years ago, we identified the coppercatalyzed azide-alkyne cycloaddition ${ }^{[9]}$ (CuAAC hereafter) as an extremely valuable tool for this purpose. ${ }^{[10]}$ Indeed, this has often been our first choice to immobilize chiral catalysts because it is a clean, orthogonal reaction that takes place under mild reaction conditions and can be followed by IR spectroscopy even on the resin beads. However, it will become evident that in other cases (especially with catalysts bearing $\mathrm{H}$-bond donors or Brønsted acids) the triazole plays a negative role and is best avoided.

This manuscript is divided in three main sections: first, a brief historical discussion will be given, followed by our approaches to immobilized organocatalysts suitable for operation in flow. Finally, a few examples of supported metal catalysts will also be discussed and compared to their metal-free counterparts.

Carles Rodríguez-Escrich (Barcelona, 1980) obtained his $\mathrm{PhD}$ from the University of Barcelona in 2008, after completing the total synthesis of Amphidinolide $X$ under the supervision of Profs. Vilarrasa and Urpí. Afterwards, he moved to the Pericàs laboratory at the ICIQ, Tarragona to work in polystyrene-supported (organo)catalysts and flow chemistry. He then spent two years (2010-2012) in the group of Prof. Karl Anker Jørgensen at the University of Aarhus, developing new organocatalytic enantioselective methods. In September 2012 he returned to the ICIQ where he is currently group coordinator of the Pericàs laboratory.

Miquel A. Pericàs (Ciutat de Mallorca, 1951) obtained his doctorate in 1979 under the guidance of Prof. Fèlix Serratosa at the Universitat de Barcelona. After postdoctoral studies at the Spanish research council (CSIC) with Prof. Francesc Camps, he joined the Universitat de Barcelona as Assistant Professor in 1980 and was promoted to Full Professor in 1991. In June 2000, he was appointed to found the Institute of Chemical Research of Catalonia (ICIQ) where he now

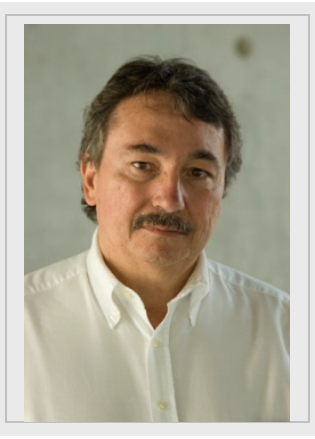

serves as Director and Group Leader. His major research interest is focused on asymmetric catalysis with immobilized species for the development of flow processes allowing the continuous production of enantiomerically pure compounds.

\section{Precedents and practical considerations}

\subsection{Early years and usual suspects}

The pioneering work of Robert B. Merrifield on solid-phase organic synthesis ${ }^{[11]}$ established a strategy that bisected homogeneous and heterogeneous chemistry, combining the advantages of both. Based on this premise, some authors decided to explore the possibility of anchoring a catalyst onto a solid support to establish whether the resulting catalytic material could be reused. $\left.{ }^{[5 a}, 5 \mathrm{~g}\right]$ Later on, the interest in obtaining enantiopure compounds spurred the development of supported chiral catalysts, which mainly involved transition metal complexes. The first example of a metal-free, supported chiral catalyst used in flow was reported in 1996, when Itsuno an co-workers used a boron-based Lewis acid to promote the Diels-Alder addition of methacrolein to cyclopentadiene. ${ }^{[12]}$ However, the first example of what we would nowadays label as flow organocatalysis came by Lectka et al., who reported a few examples of a supported Cinchona alkaloid that was able to mediate the reaction between an allene and an imine to produce $\beta$-lactams in good yields and excellent enantioselectivities. ${ }^{[13]}$

The conceptualization of organocatalysis that followed the ground-breaking works of List, Lerner and Barbas on enamine catalysis ${ }^{[14]}$ and MacMillan on iminium ion catalysis ${ }^{[15]}$ paved the way for the extension of these simple (yet hitherto elusive) concepts to hundreds of related reactions. ${ }^{[16]}$ This fever also arrived to the main players in the field of solid-supported catalysts, allured by the fact that these species would not suffer the problem of metal leaching. ${ }^{[5 c-e, 5 i, 17]}$

Nevertheless, the implementation of flow processes based on this solid-supported organocatalysts faces a significant challenge: in most cases, the batch reaction requires high catalyst loadings and long reaction times, which hampers the transition to flow in a single pass experiment. Thus, identifying a suitable heterogenized organocatalyst that works with favorable kinetics is often the bottleneck in this endeavor. Among the several authors that have been successful in this task it is worth highlighting the groups of Benaglia/Puglisi, ${ }^{[18]}$ Massi, $^{[19]}$ Fülop, $^{[20]}$ Sóos $^{[21]}$ or Wennemers. ${ }^{[22]}$

\subsection{Flexibility of the flow strategy}

An advantage of using solid-supported catalysts in flow is the flexibility of this approach. Indeed, whereas in batch the scale determines the set-up to be used, with a packed bed reactor the production of a few milligrams or multi-gram amounts of compound can be easily carried out with the same set-up, simply extending the operation time. This flexibility also enables the possibility to generate libraries of enantioenriched analogues with

the same set-up. Sequentially pumping different combinations of starting materials and rinsing for a given time before the next run one can achieve compound libraries in a straightforward manner. In comparison to the classical approach, where different products are prepared in different reaction flasks (spatial separation), flow processes allow to use a small footprint set-up to do this (temporal 
separation). Indeed, many of the examples summarized hereafter entail a long flow experiment (to prove robustness and scalability) as well as sequential experiments where libraries of analogues are prepared.

\subsection{What we speak about when we speak about flow}

Those not familiar with flow techniques might find the jargon confusing, ${ }^{[23]}$ but the underlying concepts are in general so simple that it is worth taking some time to get acquainted with the devices most commonly used. A brief list, that must be taken as a short introduction mostly related to our own work, rather than a comprehensive one, is given below. Given the importance of pictorial representations, a possible reaction set-up with the symbols of all the components is also provided (Figure 1).

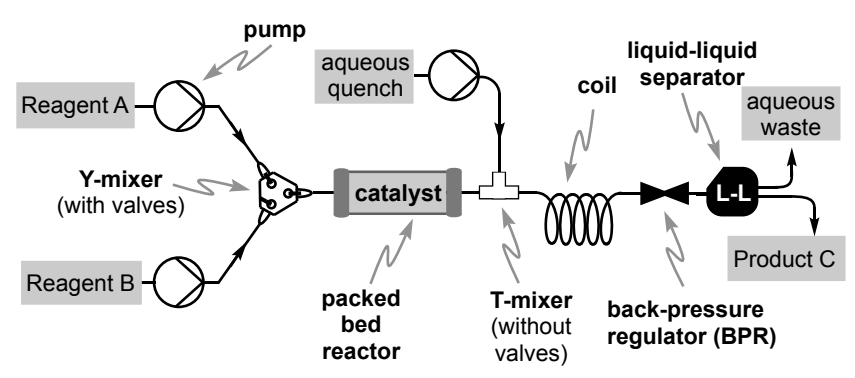

Figure 1. Schematic representation of a flow set-up with some of the devices.

PUMPS. Despite the examples by Lectka, in which the flow was forced by pressure ${ }^{[13]}$ the vast majority of flow processes require the use of pumps, which ensures a steady flow rate. There are several choices, but we tend to use regular syringe pumps or HPLC-like piston pumps.

TUBING. Most commonly PTFE tubing of $1 / 16$ " is used. For photochemical applications PFA tubing has to be employed.

PACKED BED REACTOR. This is simply a way to refer to a cylindrical piece of labware filled with the resin that has been swollen with solvent. This can be made of any material, PTFE, glass or steel. Our most common choice is a $1 \mathrm{~cm} \varnothing$ glass column, due to the fact that we do not usually require very high pressures.

CHECK VALVE. This gadget ensures that flow is unidirectional, avoiding back flow situations that can, for instance, damage the catalyst inside the packed bed reactor.

BACK-PRESSURE REGULATOR. Commonly abbreviated as $\mathrm{BPR}$, this is a device that allows to build some pressure on every part of the system that is found upstream. This allows working with gases and avoiding bubble formation with low boiling point solvents. It also enables stabilizing the flow rate of HPLC-type pumps, that are usually designed to work at high pressures.

FLOW IR. A device, with its associated software, that allows to obtain real-time information of the system by recording periodical samples of the flow stream without having to stop or open the system.
LIQUID-LIQUID SEPARATOR. A piece of equipment that enables the separation of a biphasic mixture in flow regime by virtue of their different polarities. It is a crucial gadget to perform in-line work-ups.

RESIDENCE TIME. For a given set-up, operated at a given overall flow rate, it is the time the reactants are inside the column, in contact with the catalyst. The interesting parameter is the residence time for complete conversion in single-pass operation. Residence time is not equivalent to reaction time in batch operation, although both parameters provide an indication of the efficiency of the catalyst under a given set of reaction conditions.

ACCUMULATED TON vs. YIELD. In flow operation the amount of product generated in a given catalytic experiment is best expressed by the accumulated TON rather than by yield (a parameter best suited for batch operation). In the case of a nondeactivating catalyst, accumulated TON is simply given by the product of catalyst TOF by operation time. Then, the molar amount of catalyst in the packed bed reactor provides direct information on the expected production in a given period of operation.

\section{Immobilized Organocatalysts for Work in Flow}

\subsection{Proline-based}

The proline-catalyzed direct aldol reaction was a big breakthrough in asymmetric catalysis: suddenly, a reaction that required preformation of an enolate equivalent and most likely a chiral auxiliary, could be carried out with proline in exceedingly high enantioselectivities. The rationalization behind the work of List, Lerner and Barbas, ${ }^{[14]}$ that finally gave rise to the Houk-List model, ${ }^{[24]}$ established a solid yet simple theoretical base that could be translated to many other reaction partners. Given our previous experience in solid-supported ligands for organozinc addition to aldehydes, ${ }^{[25]}$ we were curious to see how this concept would embrace organocatalysis. Thus, we anchored a hydroxyproline derivative onto a Merrifield-type resin using three different strategies: direct substitution using the free hydroxy group, or the two possible combinations of azide and alkyne via CuAAC (1-3, Figure 2). ${ }^{[26]}$

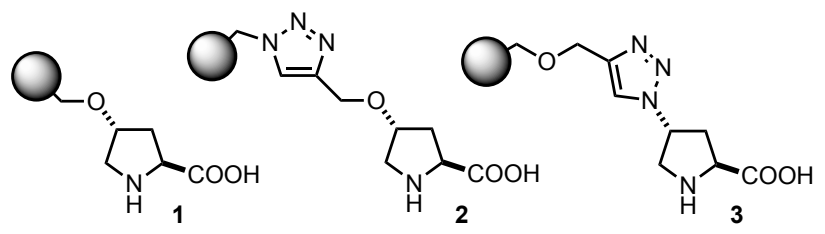

Figure 2. Early polystyrene-supported proline derivatives developed in our group.

Not surprisingly, the simplest approach (1) rendered a system that was too close to the polymer backbone, which significantly affected the catalytic activity. On the other hand, the two 
alternative triazole-based supported catalysts showed a good catalytic profile. To our surprise, $\mathbf{3}$ turned out to swell in water, a pretty uncommon feature for a polystyrene resin. Calculations point to a hydrogen bond network between the triazole and the carboxylate as the responsible for this unexpected behavior. ${ }^{[26 b]}$ After testing the performance of $\mathbf{2}$ and $\mathbf{3}$ in the aldol reaction in batch, we turned our attention to other electrophiles. In particular, imines proved very convenient and the resulting Mannich adducts were produced in very good results, both with aldehydes and ketones as donors. The fast reaction rates prompted us to consider the implementation of a flow experiment (Figure 3). To this end, we packed 2 in a simple 1/4" PTFE tube and pumped a

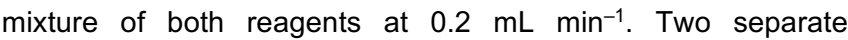
experiments provided the corresponding products with very good results, replicating the batch process but with higher productivities. ${ }^{[27]}$

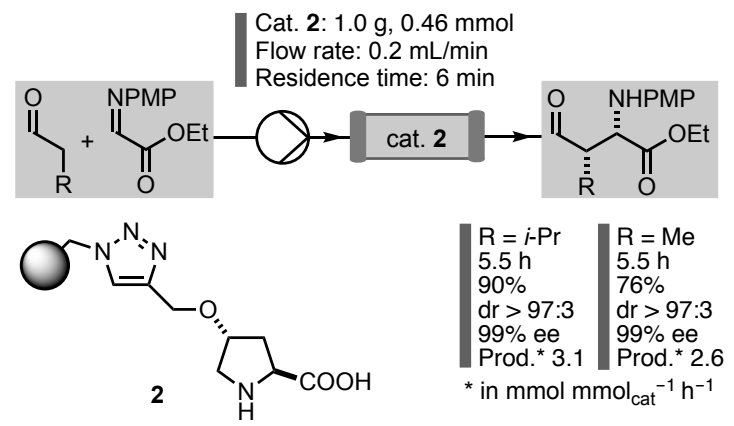

Figure 3. Polystyrene-supported proline for the Mannich reaction in flow.

Not long before, Seeberger had published a related paper dealing with the homogeneous, proline-catalyzed asymmetric aldol reaction in a microreactor. In that case, however, the catalyst loading was set from the beginning, whereas using supported catalysts the TON is a function of time: the longer the system is running, the lower the overall catalyst loading and the higher the accumulated TON. ${ }^{[28]}$ The conclusion drawn from comparing both strategies is clear: to compensate for the cost of immobilization, supported catalysts must be very robust and allow for prolonged operation time.

Encouraged by these results, we decided to explore the generality of the concept, so we moved to the $\alpha$-oxidation of aldehydes using nitrosobenzene ${ }^{[29]}$ as the electrophile. A related packed bed reactor filled with $2^{[30]}$ turned out to be very active and in 5 min residence time the desired products were obtained in good conversions $^{[31]}$ (Figure 4$)$. However, the practicality of this process was hampered by a side reaction of the catalyst that led to deactivation of the resin.

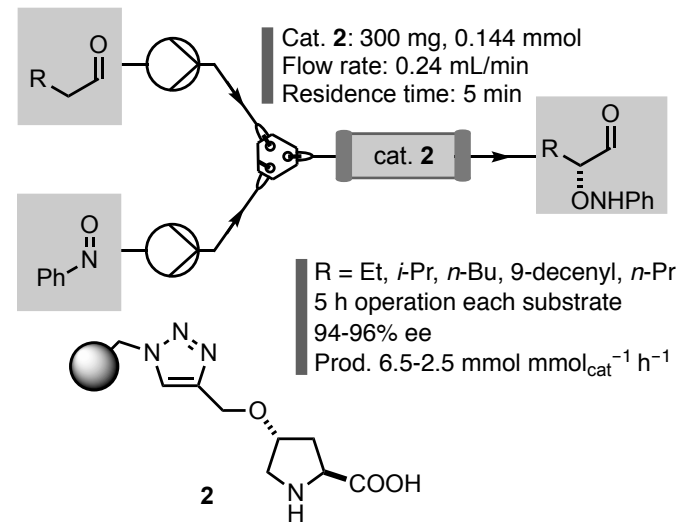

Figure 4. Immobilized proline for the flow aminoxylation of aldehydes.

Whereas aldehydes performed very well in the example of flow aldol reaction described above, ${ }^{[32]}$ ketones could be used in batch but reacted too slow to be adapted to flow. Accordingly, we set out to find a system that would be able to admit ketones as the donor component in the aldol reaction. To increase the reaction rate, an analogue of $\mathbf{3}$ with a longer linker was prepared; a higher degree of cross-linking was also used to prevent possible mechanical degradation of the resin. The resulting catalyst 4 proved competent in the aldol addition of cyclohexanone to benzaldehydes. Due to its resemblance with 3 , we assessed the impact of water as the solvent, finding that a $D M F / \mathrm{H}_{2} \mathrm{O}$ mixture was the ideal choice.

It has been proven that proline has some tendency to decarboxylate in water-free environments. ${ }^{[33]}$ Thus, we envisaged that these reaction conditions would give rise to a flow experiment that would remain active for a long time. The sluggish kinetics imposed a rather slow flow rate of $25 \mu \mathrm{L} \mathrm{min}{ }^{-1}$, but with only 600 $\mathrm{mg}$ of $\mathbf{4}$ the continuous production of the aldol derivative was running for $45 \mathrm{~h}$, with good conversions and $97 \%$ ee, which remained constant for the whole process. ${ }^{[34]}$ With the same system, four different aldehydes were reacted in a sequential manner, replicating the enantioselectivities recorded in batch (Figure 5).

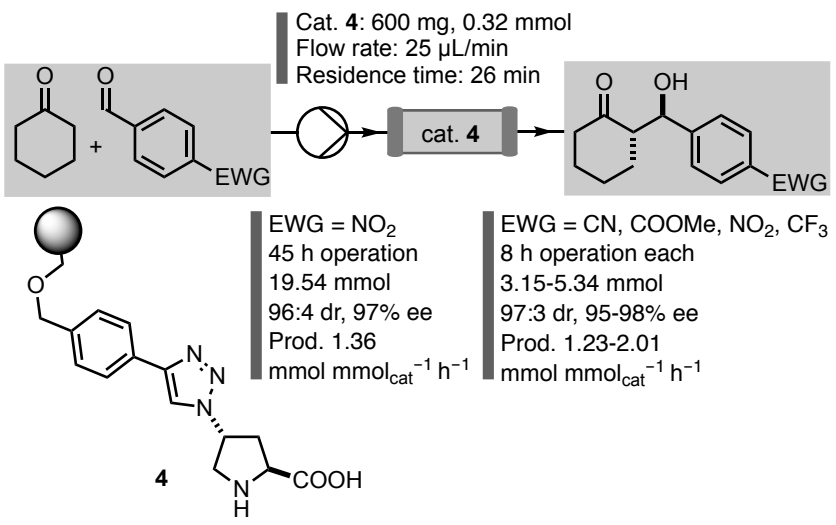

Figure 5. Continuous aldol reaction of ketones and aldehydes 


\subsection{Diarylprolinol Derivatives}

Formally related to proline, but with their own reactivity profile, are the diarylprolinol organocatalysts ${ }^{[35]}$ developed by the groups of Jørgensen ${ }^{[36]}$ and Hayashi. ${ }^{[37]}$ Whereas proline is mainly restricted to the enamine activation mode, diarylprolinols are also competent in the iminium ion pathway, which makes them ideal candidates for cascade reactions: ${ }^{[38]}$ one must bear in mind that the Michael addition to an $\alpha, \beta$-unsaturated iminium ion gives rise to an enamine, that may continue to react in the presence of a proper electrophile.

These appealing features encouraged us to study the heterogenization of a Jørgensen-Hayashi diarylprolinol catalyst onto polystyrene, as well as its catalytic behavior. The first examples involved the reaction between Michael addition of aldehyde to nitroalkenes in batch promoted by $5^{[39]}$

Later on, we studied the cascade process between enals and oxodiesters that produced cyclohexanols after a reductive treatment. ${ }^{[40]}$ The fast reactions observed in batch called for the implementation of a flow process, that is depicted in Figure $6 .{ }^{[41]}$

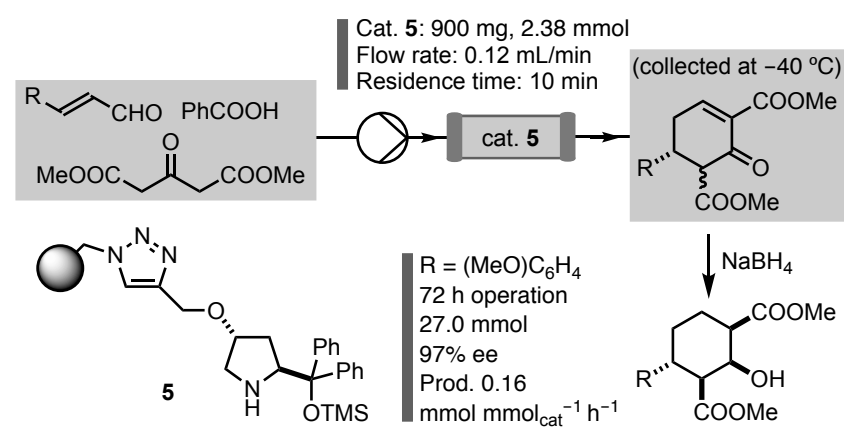

Figure 6. Supported diarylprolinol silyl ether for a flow cascade reaction.

In this case, a final reduction step was necessary to install the full array of 4 consecutive stereocentres. Owing to the inconvenience of working with $\mathrm{NaBH}_{4}$ in flow, ${ }^{[42]}$ this step was carried out in batch, after collecting the outstream over a cooling bath.

Due to concerns regarding the stability of the labile TMS group on the oxygen, and with the aim of increasing the robustness of the supported diarylprolinol, alternative silyl groups were considered. ${ }^{[43]}$ Catalyst $\mathbf{6}$, bearing a tert-butyldimethylsilyl (TBS) group showed a good compromise between reactivity, enantioselectivity and stability, so it was applied to the $\alpha$ amination of aldehydes with azodicarboxylates. ${ }^{[44]}$ In batch, this reaction gave problems due to the addition of catalyst 6 onto the azodicarboxylate, which could be solved by slow addition of the electrophile. In flow, however, this technical solution was not possible, so we had to increase the concentration of aldehyde (5fold excess) to favour the enamine formation pathway over the addition to the azodicarboxylate. With this premise, the flow experiment was carried out at $0.15 \mathrm{~mL} \mathrm{~min}^{-1}$ for a total operation time of $8 \mathrm{~h}$, the residence time being as low as $6 \min ^{[45]}$ (Figure 7).

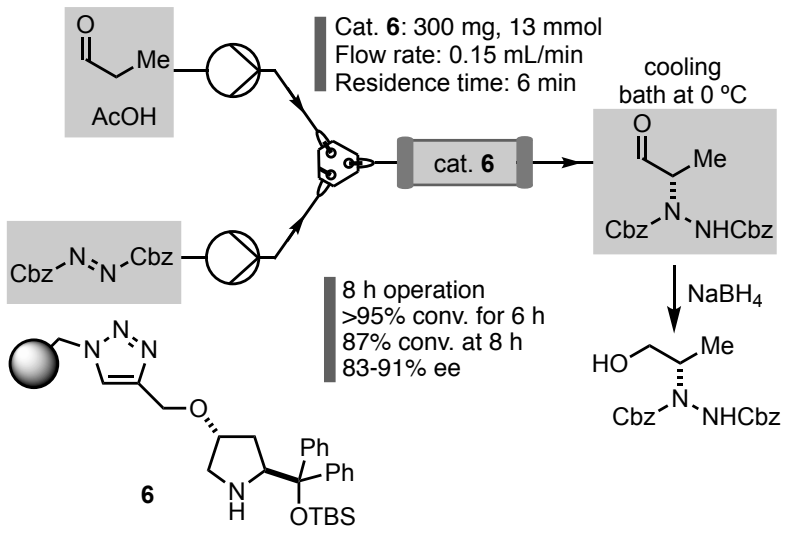

Figure 7. $\alpha$-Amination in flow promoted by an immobilized diarylprolinol catalyst.

While not strictly speaking a diarylprolinol, the fluorinated analogue known as the Gilmour catalyst ${ }^{[46]}$ has proven an interesting alternative to the Jørgensen-Hayashi type catalysts. On our quest for more stable supported aminocatalysts, we reasoned that this would make an ideal candidate due to the sturdy $\mathrm{C}-\mathrm{F}$ bond. This time, instead of using a commercially available Merrifield-type resin, we evaluated an alternative that consisted of preparing a vinyl-substituted precursor and copolymerizing it with styrene (no DVB was required, as the monomer played the role of the cross-linker as well). The resulting immobilized catalyst 7 was tested in the Michael addition of aldehydes to nitroalkenes ${ }^{[47]}$ in a project carried out in collaboration with the group of Gilmour. After finding the optimal reaction conditions, which involved the use of 4-nitrophenol as an acidic additive, we found that trace amounts of water were beneficial, while oxygen contributed to catalyst degradation. With this knowledge, we focused on the batch-to-flow transition, that

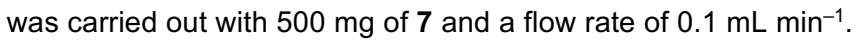
A long experiment spanning $13 \mathrm{~h}$ proved the robustness of 7 , that recorded full conversion for the first $10 \mathrm{~h}$, slightly decaying after that (Figure 8).

Another benefit of working in flow is the possibility of carrying out in-line work-up procedures. In this case, the 4-nitrophenol additive was efficiently removed by adding an extra pump with an aqueous $\mathrm{NaOH}$ solution downstream of the column. In the resulting plug flow situation, with tiny aqueous and organic phases successively passing through the coil, the base deprotonated 4-nitrophenol, giving the aqueous layer a distinctive yellow colour. To separate this mixture, that traditionally would have been poured onto an extraction funnel and decanted, a liquid-liquid separator was employed (vide supra). This small device efficiently removed the aqueous stream, leaving the organic one so clean that if the aldehyde (only reagent in excess) was volatile, simple evaporation of the mixture furnished the pure product. 


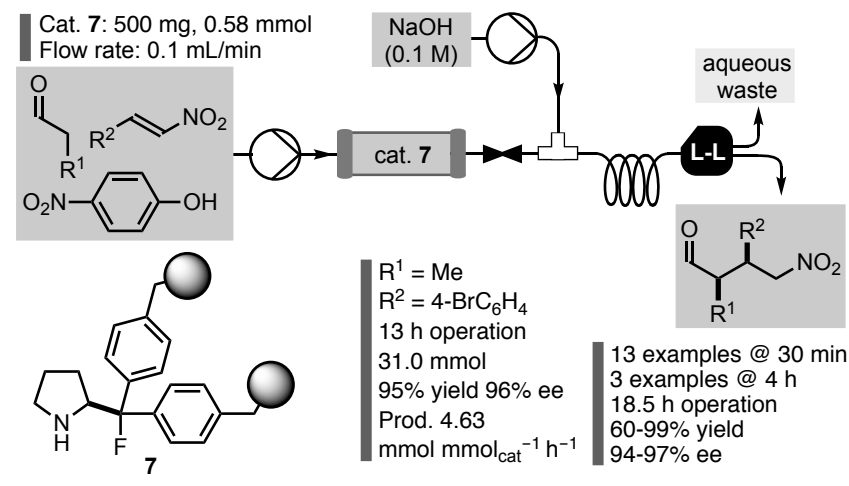

Figure 8. A co-polymerized version of the Gilmour catalyst for the continuous Michael addition of aldehydes to nitroalkenes.

To further prove the advantages of the flow system, the same setup was used to prepare a library of 13 different analogues, by sequentially pumping the corresponding reagent combination for 30 minutes and rinsing for $1 \mathrm{~h}$ with solvent. Since the packed bed reactor was still fully active after this, larger amounts of three of the substrates were prepared in 4-h experiments. This is a good example of the flexibility of flow processes: with the same set-up one can easily change the scale of the reaction without having to bother about technical issues.

Another point worth emphasizing is that, in line with the previous finding that oxygen was detrimental for the reaction, we found that drying the column between runs severely affected its reusability. Therefore, during the three days it took to run the sequential generation of the library, the flow was not stopped, but kept overnight under a stream of $\mathrm{CH}_{2} \mathrm{Cl}_{2}\left(25 \mu \mathrm{L} \mathrm{min}{ }^{-1}\right)$.

So far, we have seen how the immobilization strategy can affect the reaction outcome. The presence of a triazole group, for instance, can either improve the results, expand the solvent choice or shut down the reactivity, depending on the reaction being studied (vide infra, as well). However, the selection of the solid support rarely undergoes a casting aimed at identifying the most suitable alternative. In order to dig into this issue, we selected the diarylprolinol-catalyzed cyclopropanation of $\alpha, \beta-$ unsaturated aldehydes ${ }^{[48]}$ as a touchstone. Thus, a library of supported catalysts (8-10) was prepared with two points of diversity: the type of resin and the immobilization strategy. ${ }^{[49]}$ For the resin, we chose a microporous polystyrene resin (low crosslinking) or a macroporous monolith; the three immobilization strategies to be compared were (a) a hydroxyproline with a benzylic linker (8), (b) a triazole-based 9 and (c) a copolymerization approach analogous to the one followed for $10,{ }^{[47]}$ (Figure 9).

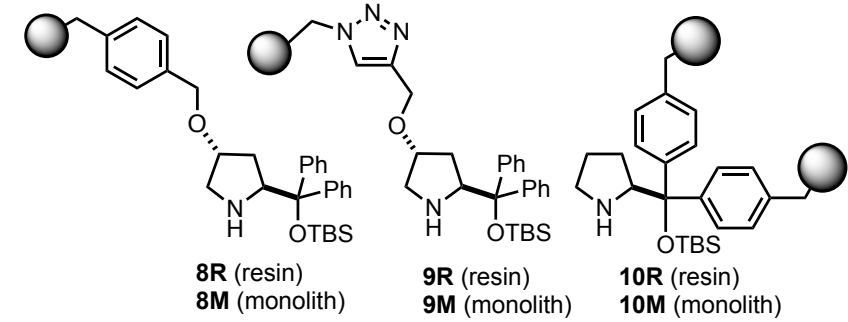

Figure 9. Immobilized catalysts prepared for the asymmetric cyclopropanation.

Catalysts 8-10 were thus tested in batch in the above-mentioned cyclopropanation reaction; the results show that the parameters under study significantly affect the performance of the resin. The most successful ones, resin $\mathbf{8 R}$ and monolith $\mathbf{9 M}$, were evaluated in long flow experiments spanning more than $24 \mathrm{~h}$. Whereas $9 \mathrm{M}$ experienced a catalytic decay after $24 \mathrm{~h}$, the flow process with resin $\mathbf{8 R}$ (lacking the triazole group) was running for $48 \mathrm{~h}$, the ee's remaining constant through the whole process. The same packed bed reactor was then used to react dimethyl bromomalonate with 12 different $\alpha, \beta$-unsaturated aldehydes in a sequential manner. Each example was run for $6 \mathrm{~h}$, before rinsing the column with solvent and moving to the next run (Figure 10). Perhaps the most remarkable feature of $\mathbf{8} \mathbf{R}$ is the robustness displayed: the sequential library generation was carried out with the same packed bed reactor over a period of one year.

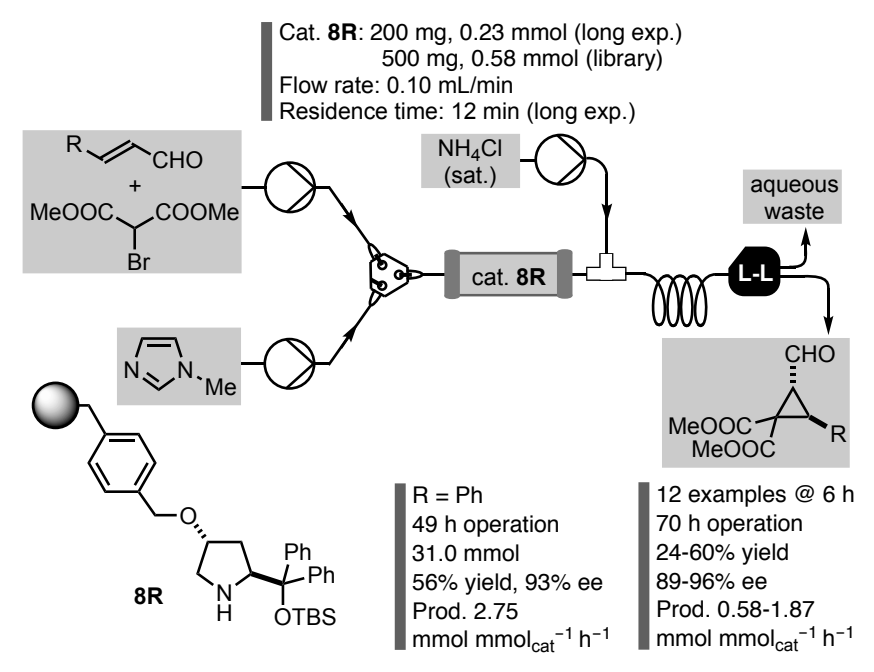

Figure 10. Continuous flow asymmetric cyclopropanation.

\subsection{Other Aminocatalysts}

Even if they might be the most paradigmatic examples, there is much more to aminocatalysis beyond proline and diarylprolinols. Therefore, other successful primary and secondary amines have been immobilized and evaluated in asymmetric flow processes.

Along these lines, we developed pyrrolidine derivative 11 in our laboratories and applied it to the anti-selective Mannich addition of aldehydes and ketones to imines. ${ }^{[50]}$ The modularity of this 
catalyst facilitated the preparation of $\mathbf{1 2}$, a solid-supported version that resorted once more to a triazole-based linker. ${ }^{[51]}$ The outstanding activities recorded with 12 (low catalyst loadings, short reaction times and high enantioselectivities) called upon the implementation of a flow process. A set of aldehydes/ketones and imines was circulated through the system depicted in Figure 11 giving rise to a small library of anti-Mannich adducts. In this case, however, it is worth highlighting two experiments in particular, that were operative for more than two days each, reaching TONs close to 300 and producing up to $21 \mathrm{~g}$ of a Mannich adduct.

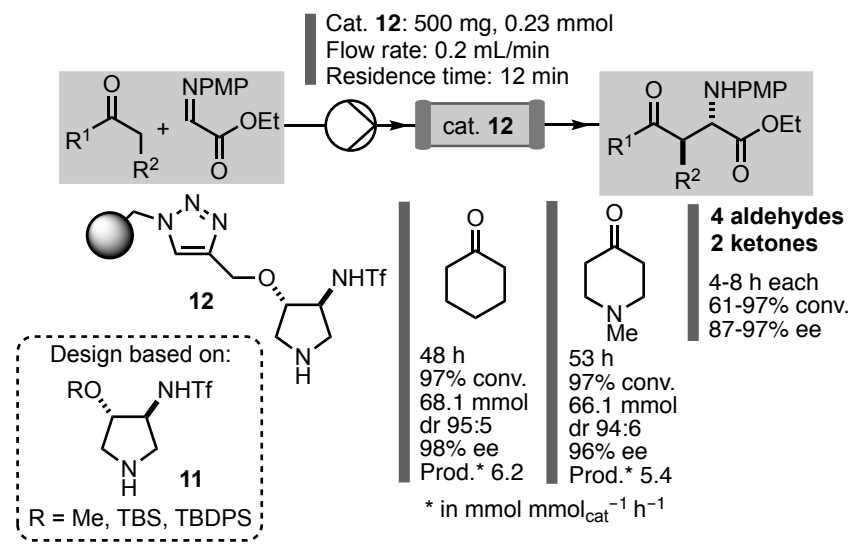

Figure 11. anti-Selective Mannich reaction in flow promoted by a polystyrenesupported pyrrolidine derivative.

Primary amino acids have also been shown to make good catalysts, albeit whereas secondary ones (e.g. proline and derivatives) work better with aldehydes, these are more prone to ketone activation. ${ }^{[52]}$ In 2014, we reported on the three-component Mannich reaction between hydroxyacetone and glyoxylate imines, that gives an aminohydroxylated compound. ${ }^{[53]}$ To promote this transformation, we immobilized six primary amino acids, of which threonine derivative 13 resulted the most promising one. Even if the flow rates were rather low, the three-component reaction could be translated to a continuous regime as depicted in Figure 12. Two different anilines were tested in long experiments (6 and $4 \mathrm{~h}$ ) giving the desired Mannich adducts in up to $3.13 \mathrm{mmol}$. After that, a library of five analogues was prepared in a succession of one-hour experiments with good productivities.

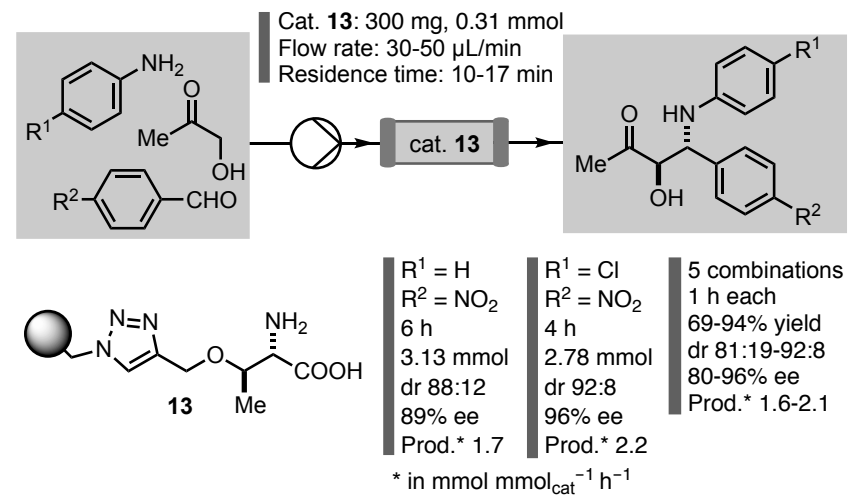

Figure 12. Three-component Mannich reaction with an immobilized threonine
Cinchona alkaloids derivatives occupy a central position amongst primary amine organocatalysts, as demonstrated by several authors. ${ }^{[54]}$ Their ability to form enamines with ketones and the presence of other functional groups (quinuclidine and quinoline) make them very versatile catalysts with broad applicability. However, this array of functionalities makes the anchoring of such scaffolds far from straightforward. We decided to use the quinuclidine vinyl group for that purpose, which gave rise to the triazole-linked resin 14 in four synthetic steps. ${ }^{[55]}$ The reaction of choice this time was the Michael addition of $\alpha$-nitroesters to enones, ${ }^{[56]}$ given the already mentioned ketone preference of primary amines. The high acidity of the nucleophile entailed low diastereoselectivities, but the enantiomeric excesses were usually very good. Following the usual test to prove robustness and versatility, $450 \mathrm{mg}$ of $\mathbf{1 4}$ were packed in a column and the two reagents were pumped in a single stream at $50 \mu \mathrm{L} \mathrm{min}-1$. In this manner, $12.9 \mathrm{mmol}$ of the Michael adduct were isolated in $98 / 97 \%$ ee in a total of $21 \mathrm{~h}$ operation time (Figure 13). The sequential library generation in flow was carried out for 5 different analogues ( $1 \mathrm{~h}$ each, $1 \mathrm{~h}$ rinsing in between runs) giving the corresponding products in $85-99 \%$ ee.
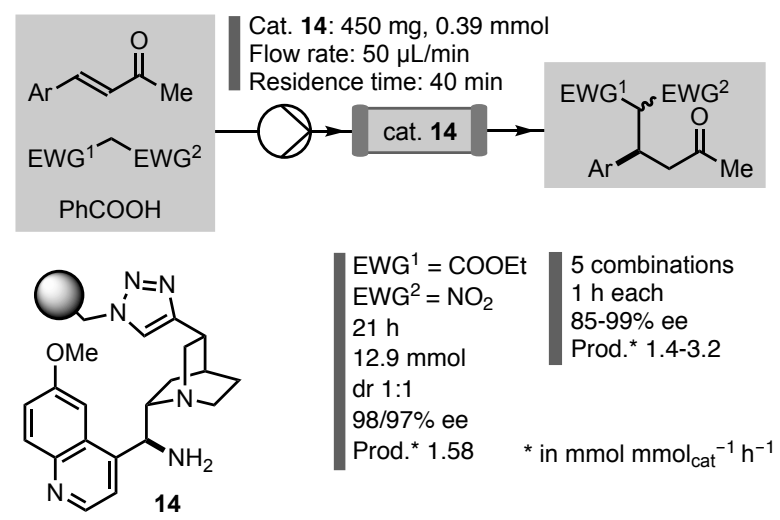

Figure 13. Supported Cinchona-derived primary amine for flow conjugate addition.

The Robinson annulation ${ }^{[57]}$ is a classic reaction that has been broadly applied to the synthesis of countless natural products and steroid derivatives. Despite the classic reports on prolinecatalyzed, asymmetric Robinson annulation by the groups of Hajos/Parrish ${ }^{[58]}$ and Eder/Sauer/Wiechert, ${ }^{[59]}$ that are a landmark in organocatalysis, a recyclable catalyst that works at reasonable rates remained elusive. Motivated by a report where Luo and coworkers applied their diamine 15 to this reaction, ${ }^{[60]}$ we embarked in a project aimed at immobilizing this catalyst onto a solid support and apply it to the enantioselective Robinson annulation. A synthetic sequence that hinged on the preparation of a chiral aziridine furnished 17 (without triazole linker in this case) in six steps from tert-leucine. To our delight, going from room temperature to $55^{\circ} \mathrm{C}$ with resin 17 , did not affect the ee's, but the reaction times were reduced by a 10 -fold. ${ }^{[61]}$ Strikingly, its homogeneous analogue 16 did not show such a significant improvement when heating up, indicating that the interplay of polymer and temperature generates a special situation. 
These fast kinetics, together with its proven recyclability, enabled the deployment of $\mathbf{1 7}$ in a continuous flow experiment with a jacketed packed bed reactor heated at $60^{\circ} \mathrm{C}$. A couple of adjustments had to be done before. Firstly, the low solubility of some substrates in 2-methyltetrahydrofuran forced us to use DMF instead. Secondly, methyl vinyl ketone was found to react with the catalyst, so the first step of the reaction had to be carried beforehand. This was solved by using a polymer-supported DBU, which yielded the clean meso-compound that could be directly pumped in the system after filtration. With these precautions, a 24-h flow experiment allowed the preparation of $11.7 \mathrm{~g}$ of the Wieland-Miescher ketone in $91 \%$ ee, for an overall TON of 117 . A similar set-up was used to prepare a library of eight chiral biand tricyclic cylohexenones in up to $94 \%$ ee (Figure 14).

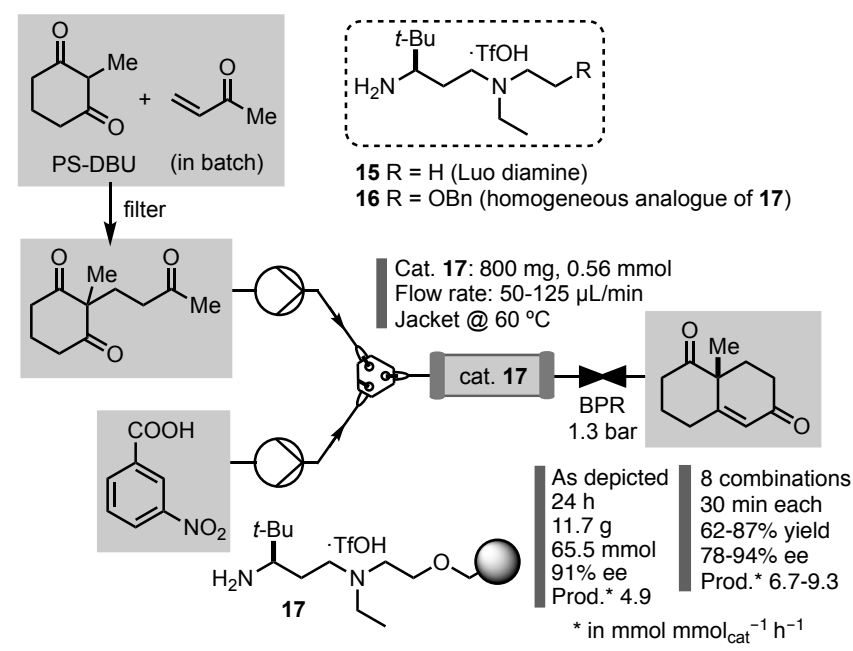

Figure 14. Immobilized chiral diamine catalyst for the flow Robinson annulation.

\subsection{Squaramides}

The term organocatalyst encompasses much more than amines. Hydrogen bond donors, for instance, have proven extremely successful, especially when they are integrated in a bifunctional catalyst bearing an additional basic center. A good example of this are the chiral squaramide catalysts, ${ }^{[62]}$ originally described by Rawal and co-workers. ${ }^{[63]}$ We postulated that Brønsted acids and $\mathrm{H}$-bond donors would be ideal candidates for immobilization, given the fact that they do not establish covalent bonds with the substrates, thus reducing the possible pathways for catalyst deactivation. ${ }^{[64]}$ On this basis, we prepared the polystyrenesupported bifunctional squaramide $\mathbf{1 8}$, that proved highly active and selective in the Michael addition of active carbonyl compounds to nitroalkenes. ${ }^{[65]}$ Even more importantly, it was a very robust material that could be recycled at least ten times. The low catalyst loadings and short reaction times encouraged us to test this immobilized squaramide in flow. After optimizing the reaction between hydroxynaphthoquinone and a set of nitroalkenes in batch, we packed $250 \mathrm{mg}$ of $18(<0.1 \mathrm{mmol})$ in a glass column and pumped a mixture of both reagents at $0.2 \mathrm{~mL}$ $\mathrm{min}^{-1}$ flow rate ${ }^{[66]}$ (Figure 15). This minute amount of catalyst allowed to maintain a flow experiment active for $20 \mathrm{~h}$. The enantioselectivity remained constant during the whole process $(96 \%$ ee) and $6.6 \mathrm{~g}$ of the desired product were isolated, which corresponds to an accumulated TON of 200 and a productivity of $10.7 \mathrm{mmol} \mathrm{mmol}_{\mathrm{cat}}{ }^{-1} \mathrm{~h}^{-1}$. Resin 18 also proved amenable for the production of libraries of compounds, as demonstrated by a sequential experiment in which $500 \mathrm{mg}$ of this supported squaramide catalyst were used to prepare six different analogs in high yields and enantiomeric excesses.

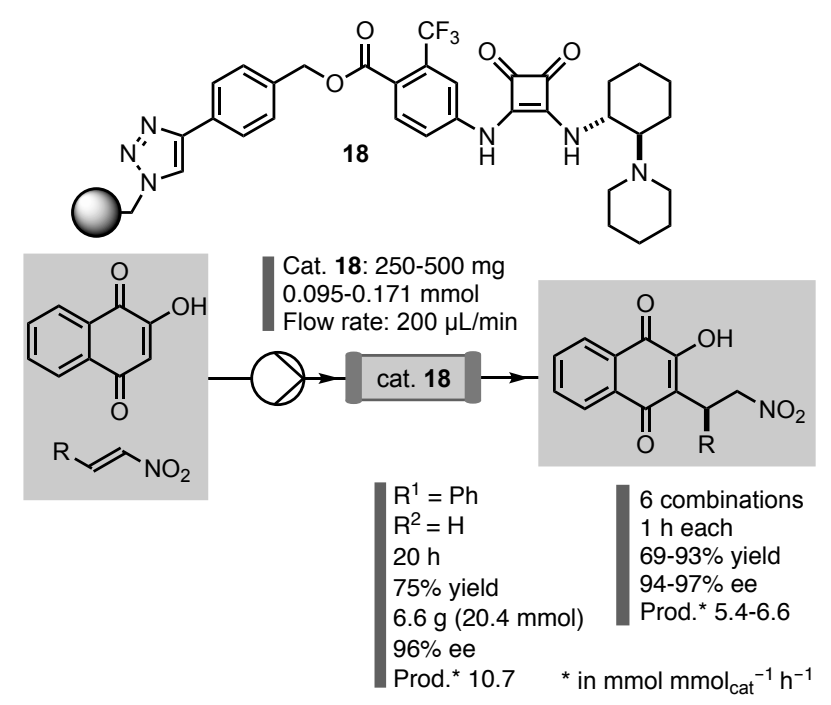

Figure 15. Supported squaramide catalyst for the continuous conjugate addition of hydroxynaphthoquinones to nitroalkenes.

Concerned by the tedious and costly preparation of $\mathbf{1 8}$, we embarked in a project aimed at determining how much we could simplify its synthesis. Using the reaction between hydroxynaphthoquinone and $\alpha$-acetoxymethylnitroalkenes ${ }^{[67]}$ as the benchmark reaction, we could establish that the trifluoromethyl group in $\mathbf{1 8}$ did not play any particular role, whereas the triazole was merely a spacer. These studies allowed the preparation of 19 , a much simpler squaramide catalyst that proved even more active and selective than 18. In contrast to the original reports in homogeneous, ${ }^{[67]}$ we had to add base to complete the cyclization reaction. Thus, a telescoped flow system consisting of a column packed with $400 \mathrm{mg}$ of 19 , followed by an additional pump with $\mathrm{NaHCO}_{3}$ (aq.) and a $10-\mathrm{mL}$ coil, was assembled. While the role of 19 was to promote the enantioselective Michael addition, the basic in-line work-up effected the elimination-oxa-Michael cyclization that gives rise to the final product. Working at a flow rate of $0.2 \mathrm{~mL} \mathrm{~min}-1$, a library of seven analogues could be prepared in good yields and excellent enantioselectivities ${ }^{[68]}$ (Figure 16). 


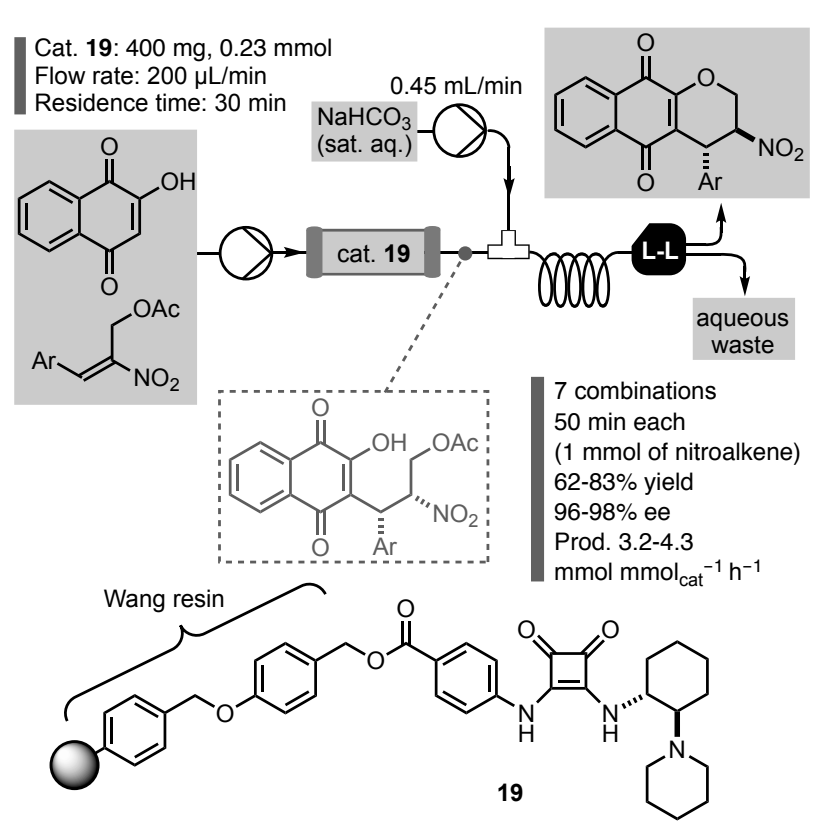

Figure 16. Flow synthesis of pyranonaphthoquinones with a simplified supported squaramide catalyst.

\subsection{Thioureas}

Formally related to squaramides, ureas and thioureas were the first $\mathrm{H}$-bond donors to be used in asymmetric catalysis, thanks to the pioneering works by Jacobsen ${ }^{[69]}$ and Takemoto. ${ }^{[70]}$ The ability of thioureas to coordinate to carbonyl compounds or nitro groups, and to abstract anions, has been exploited in several catalytic asymmetric transformations. Lured by the anticipated robustness of the thiourea moiety, we set out to study the immobilization of a bifunctional thiourea-cyclohexandiamine derivative, while trying to evaluate the influence of the linker. Indeed, the presence of a triazole handle led to poorly reproducible results, arguably due to trace amounts of copper remaining from the immobilization step. Consequently, we prepared $\mathbf{2 0}$, devoid of triazole, that was anchored by simple nucleophilic displacement of the chloride by a carboxylate. While anchoring the monomer as late as possible is generally a safer strategy to safeguard the identity of the supported species, in this case the reliability of the reaction sequence allowed the solid phase synthesis of 20. ${ }^{[71]}$ This was employed in the amination of $\beta$-dicarbonylic compounds (ketoesters and diketones) with azodicarboxylates. ${ }^{[72]}$ Resin 20 turned out to be fairly active for 7- and especially 5-membered cyclic substrates, but cyclohexanone derivatives and aliphatic ones were reluctant to participate in the reaction. For the flow experiment, $300 \mathrm{mg}$ of $\mathbf{2 0}$ were packed in the reactor and the mixture of reagents was circulated at $50 \mu \mathrm{L} \mathrm{min}^{-1}$. On the basis of the batch experiments, where loss of activity could be deterred by treatment with base, every $2 \mathrm{~h}$ of operation we performed a reconditioning procedure consisting of washing the reactor with $\mathrm{Et}_{3} \mathrm{~N}$ in $\mathrm{CH}_{2} \mathrm{Cl}_{2}$. Under these conditions, $7.5 \mathrm{~h}$ of effective operation were enough to produce $1.81 \mathrm{~g}$ of the amination product in $71 \%$ yield and $93 \%$ ee (Figure 17 ).

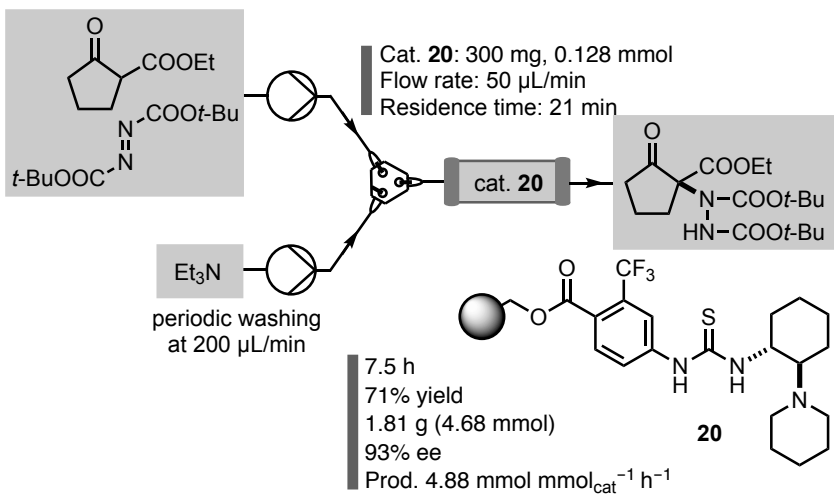

Figure 17. Immobilized thiourea for the enantioselective amination of ketoesters.

\subsection{Phosphoric Acids}

Guided again by the hypothesis that the lack of covalent interactions between substrate and catalyst increases the lifetime of the latter we turned our attention to chiral phosphoric acids. These, independently developed by Akiyama ${ }^{[73]}$ and Terada ${ }^{[74]}$ in 2004 for the activation of imines, have proven very versatile, displaying a significantly broad scope. ${ }^{[75]}$ Previous reports in the literature had either relied on co-polymerization of vinylated intermediates or exploited the innate ability of thiophene residues to polymerize. ${ }^{[76]}$ In contrast, our first attempt hinged in the preparation of a BINOL derivative functionalized in position 6 , which allowed anchoring through etherification of chloromethylpolystyrene. Formation of the phosphoric acid gave rise to the desired catalyst $21,{ }^{[77]}$ that was evaluated in the azaFriedel-Crafts addition of indoles to $\mathrm{N}$-tosylimines. ${ }^{[78]}$ Working in batch, the addition products were isolated in good yields and ee's and 21 could be repeatedly re-used. During these recycling studies, we found the most remarkable feature of 21: the catalytic activity lost upon recycling could be restored by simply reconditioning the resin with $\mathrm{HCl}$ in EtOAc.

These results prompted us to pack $360 \mathrm{mg}$ of $21(<0.1 \mathrm{mmol})$ to study the related flow process. Up to $3.6 \mathrm{~g}$ of the addition product were isolated after six hours at $0.2 \mathrm{~mL} \mathrm{~min}^{-1}$; the conversion and yield remained constant during the whole process and the productivity reached as high as $17.0 \mathrm{mmol}_{\mathrm{mmol}_{\mathrm{cat}}}{ }^{-1} \mathrm{~h}^{-1}$. Afterwards, the same packed bed reactor was applied to the sequential production of five analogues with similarly high productivities (Figure 18). It is worth emphasizing that the use of a flow IR device allowed to collect information of the system in real time. The use of in-line analysis, together with the in-line work-ups previously discussed, is deemed crucial for the implementation of flow chemistry in industrial environments. This strategy has a direct impact on the footprint of the reactors, allowing significant reduction of their overall volume. 


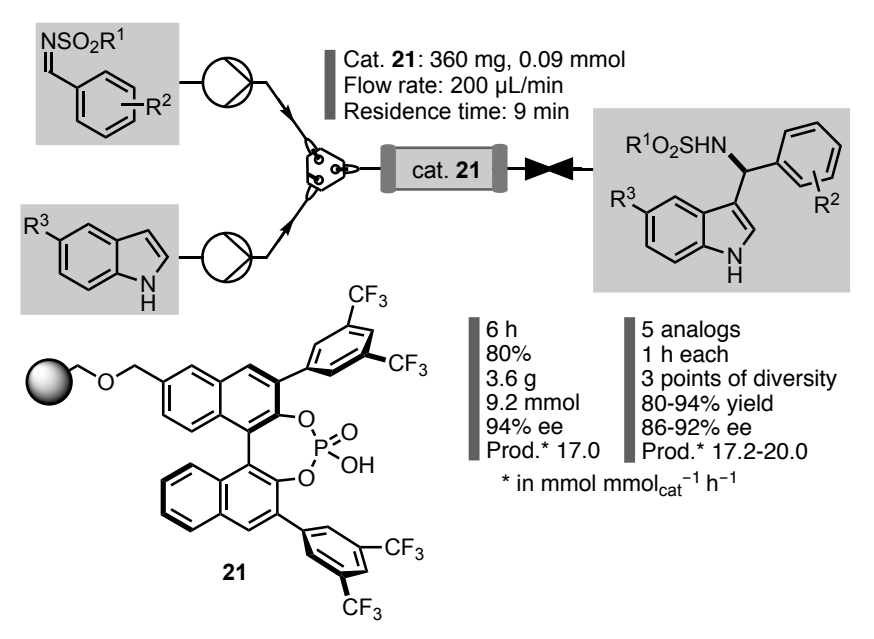

Figure 18. Solid-supported chiral phosphoric acid-catalyzed Friedel-Crafts addition of indoles to sulfonylimines.

The robustness of $\mathbf{2 1}$ motivated us to study the immobilization of TRIP catalyst developed by List, ${ }^{[79]}$ perhaps the most versatile phosphoric acid derivative reported to date. The synthesis of a polystyrene-supported version of TRIP proved more troublesome, but co-polymerizing a conveniently functionalized BINOL derivative gave the desired catalytic material in an easy manner that required only three more steps than the homogeneous counterpart. The reaction of choice to evaluate the performance of resin 22 was the allylboration of aldehydes, reported in homogeneous by Antilla et al. ${ }^{[80]}$ The batch experiments worked smoothly to generate 18 different allylated products re-using the same sample of 22. Basic substrates deactivated the catalyst (presumably by acid-base reaction) but, as with $\mathbf{2 1}$, the activity could be restored by washing the resin with $\mathrm{HCl}$ in EtOAc. ${ }^{[81]}$

The flow process was carried out with two independent pumps due to the incompatibility of the aldehyde and the allylboronate. Downstream of the column, a third pump fed the system with aqueous $\mathrm{NaHSO}_{3}$ to scavenge the remaining aldehyde; otherwise, a background process took place, drastically reducing the recorded enantioselectivities (Figure 19). In these conditions, the flow process spanned $28 \mathrm{~h}$ at a combined flow rate of $0.2 \mathrm{~mL} \mathrm{~min}^{-}$ ${ }^{1}$, furnishing the chiral alcohol in $92 \%$ yield and $91 \%$ ee with high productivities (10.1 mmol mmolcat ${ }^{-1} \mathrm{~h}^{-1}$ ) and an accumulated TON of 282.

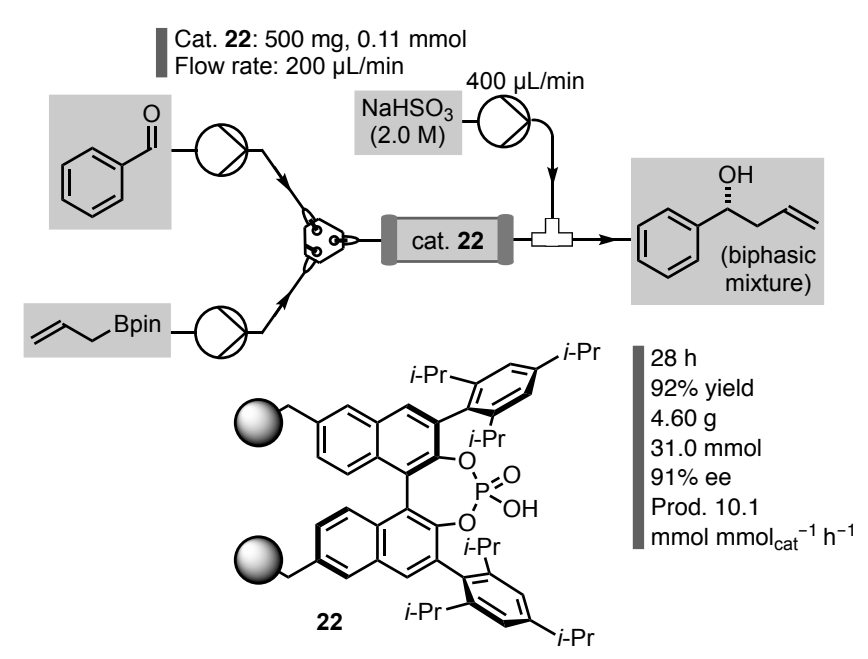

Figure 19. Polystyrene-supported TRIP for the asymmetric allylboration of aldehydes in flow.

\subsection{Isothioureas}

The chemistry of enolates is a time-honoured strategy for the construction of $\mathrm{C}-\mathrm{C}$ bonds. However, the classic methods are hampered by the need to pre-generate stoichiometric amounts of an activated intermediate, often employing strong bases. Several alternatives have been recently developed to circumvent the need to pre-form enolates, which allows working under much milder reaction conditions. In addition to the aminocatalysts, already discussed in Sections 3.1-3.3, chiral Lewis bases such as $N$ heterocyclic carbenes ${ }^{[82]}$ (NHCs) or isothioureas ${ }^{[83]}$ provide an interesting solution, enabling the generation of enolate equivalents in situ from simple precursors.

The pioneering use of chiral isothioureas in catalysis by Birman ${ }^{[84]}$ and Okamoto, ${ }^{[85]}$ has established a useful approach for kinetic resolution and asymmetric creation of $\mathrm{C}-\mathrm{C}$ bonds ${ }^{[86]}$ that has been exploited by other authors like Smith ${ }^{[87]}$ and Romo, ${ }^{[88]}$ among others. Thus, we decided to immobilize these isothioureas to assess if the associated benefits compensate the synthetic cost.

Starting from enantiopure phenylglycidol, we prepared in five steps an analog of benzotetramisole that was subsequently anchored to azidomethylpolystyrene by means of a click reaction. The resulting supported catalyst $\mathbf{2 3}^{\left[{ }^{[89]}\right.}$ was found to efficiently promote the asymmetric [4+2] addition of chiral enolates (generated in situ from the acid) to chalcone-derived sulfonyl imines. ${ }^{[87 c]}$ The scope of the reaction was very broad, tolerating substitution on both ends of the imine, as well as on the acid. We found that saccharin-derived tosylimines also participated in the reaction, leading to tricyclic molecules. After securing the recyclability of $\mathbf{2 3}$ in batch we assembled a flow system consisting of (a) two syringe pumps connected to a coil to generate in situ the mixed anhydride, (b) a second pump feeding the system with the $\alpha, \beta$-unsaturated tosylimine, (c) a packed bed reactor with 600 $\mathrm{mg}$ of 23, (d) downstream of the column, another pump with water to quench the excess anhydride and finally (e) a liquid-liquid separator to remove the aqueous waste (Figure 20). Under these 
conditions, more than $4 \mathrm{~g}$ of the resulting dihydropyridone were obtained in an enantiopure manner.

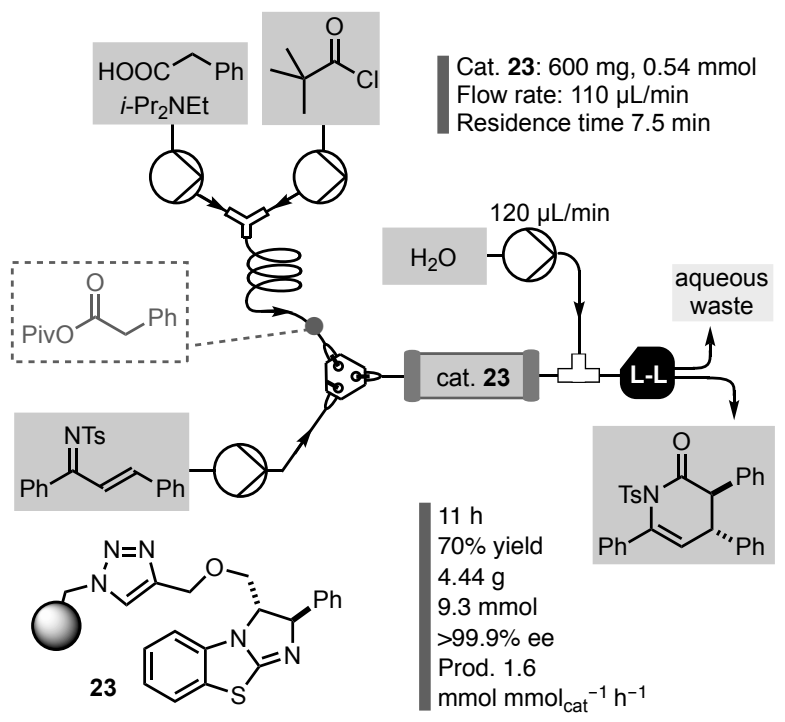

Figure 20. Immobilized isothiourea for the asymmetric synthesis of lactams in flow.

Later, we expanded the scope of $\mathbf{2 3}$ to accommodate exocyclic alkylidene pyrazolones or thiazolones as heterodienophiles, giving rise to the corresponding bicyclic products bearing two contiguous stereocentres. ${ }^{\left[{ }^{90]}\right.} \mathrm{A}$ single continuous flow experiment was carried out, using a similar set-up as in the previous case, where the mixed anhydride was produced in situ. The system was operated for $18 \mathrm{~h}$ to produce $2.74 \mathrm{~g}$ of the resulting pyranopyrazolone (Figure 21).

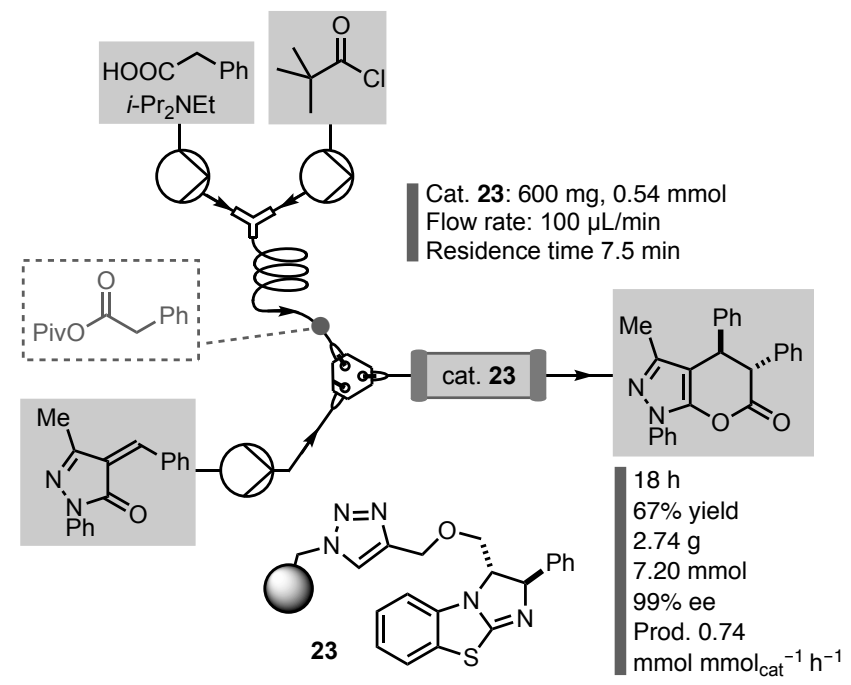

Figure 21. Flow synthesis of chiral pyranopyrazolones with a supported isothiourea.

More recently, a collaboration with the group of Andrew D. Smith form the University of Saint Andrews (Scotland) has given rise to the application of $\mathbf{2 4}$ in the kinetic resolution of alcohols in flow. ${ }^{[91]}$ (Figure 22). In batch, 24 displayed a very broad substrate scope and remarkable robustness, allowing for 15 cycles with essentially the same results. The implementation of the related flow process gave rise to a long experiment $(24 \mathrm{~h})$ and the generation of nine analogs by sequential experiments. All the examples run in flow were carried out with the same packed bed reactor, proving once more the significant stability of $\mathbf{2 4}$ for this reaction.

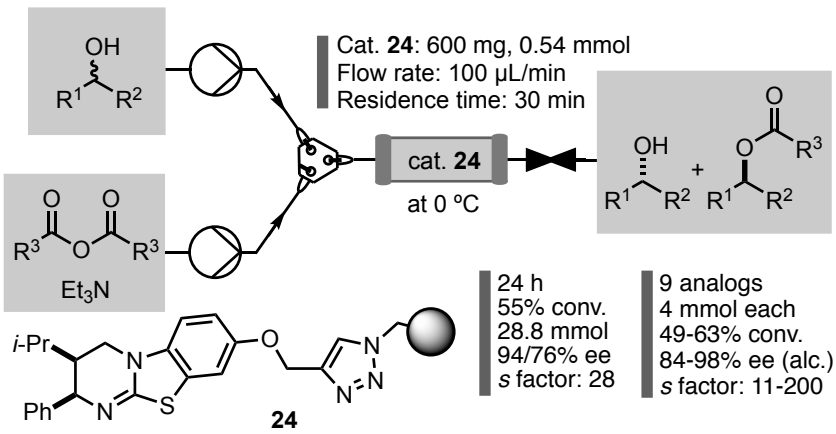

Figure 22. Isothiourea-mediated kinetic resolution of alcohols in flow.

\section{Immobilized Ligands and Metal-Based Catalysts for Work in Flow}

By now it must be quite obvious that the group expertise revolves around solid-supported organocatalysts. Nevertheless, we have also worked with immobilized ligands and metallic catalysts, which were actually our entrance door to flow chemistry. The main issue related with the use of supported metal species in flow is the leaching, which can be hard to control. ${ }^{[17]}$ In addition, the need to exclude air or moisture can hamper the implementation of such flow processes. In spite of these pitfalls, we have successfully developed a few examples of the use of immobilized metalcontaining species in continuous flow.

\subsection{Amino Alcohol Ligands}

The use of ligands to promote the alkylation and arylation of aldehydes with organozinc species is a classic strategy that allows the generation of enantiopure alcohols in a straightforward fashion. ${ }^{[92]}$ For several years our laboratory worked on this topic, developing new ligands and synthetic strategies; ${ }^{[93]}$ intrigued by the possibility of recycling the chiral ligand, we considered their heterogenization on polymer- or silica-based supports. ${ }^{[25]}$ The high levels of activity and selectivity of these materials encouraged us to study for the first time in our laboratory their deployment in a flow process.

To this end, resin-bound amino alcohol $\mathbf{2 5}$ was packed in a glass column and the aldehyde and diethylzinc solutions were circulated through the system with two independent pumps (Figure 23). In this manner, seven independent experiments gave rise to a library of benzylic alcohols using flow rates of $0.24 \mathrm{~mL}$ $\min ^{-1}$ ( $3 \mathrm{~h}$ each run); in one remarkable case, though, 4cyanobenzaldehyde could be ethylated at an astonishing $0.72 \mathrm{~mL}$ $\mathrm{min}^{-1}$, full conversion being recorded. To prove the robustness of 
the resin, three consecutive runs were carried out on the same sample of $\mathbf{2 5}$, only a slight decrease in conversion being observed. ${ }^{[94]}$

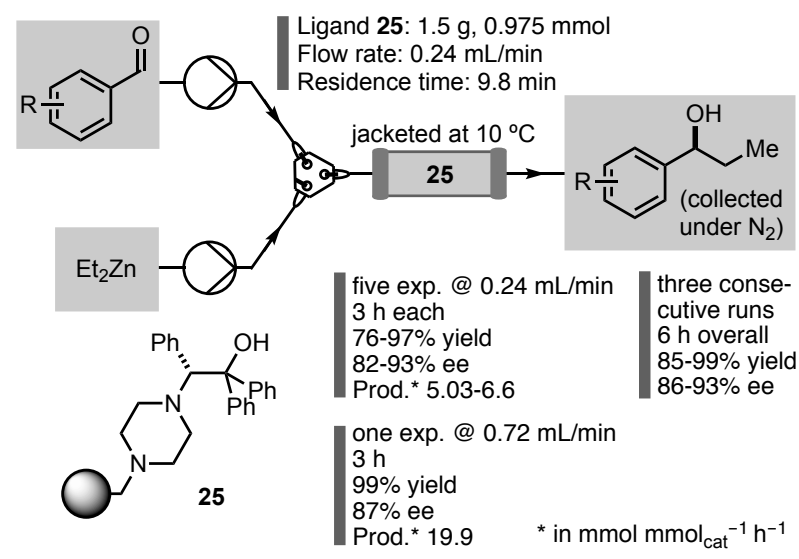

Figure 23. Aldehyde ethylation in flow.

In 2008 we published that triarylboroxins undergo a scrambling process with $\mathrm{Et}_{2} \mathrm{Zn}$ that generates in situ the corresponding arylzinc species. This strategy greatly simplified the arylation of aldehydes, avoiding the use of expensive and difficult to prepare diarylzinc derivatives. ${ }^{[93 e]}$ Hence, we reasoned that integrating this approach with the knowledge acquired on the previous work with ligand $\mathbf{2 5}$ would allow to carry out the enantioselective continuous arylation of aldehydes with triarylboroxins as the ultimate source of aryl groups.

Six different flow experiments were carried out with the set-up depicted in Figure 24, each run spanning 3-4 h. The resulting diarylmethanols were isolated, after collecting the outstream over aqueous $\mathrm{NH}_{4} \mathrm{Cl}$ and chromatographic purification, in up to $93 \%$ yield. ${ }^{[95]}$

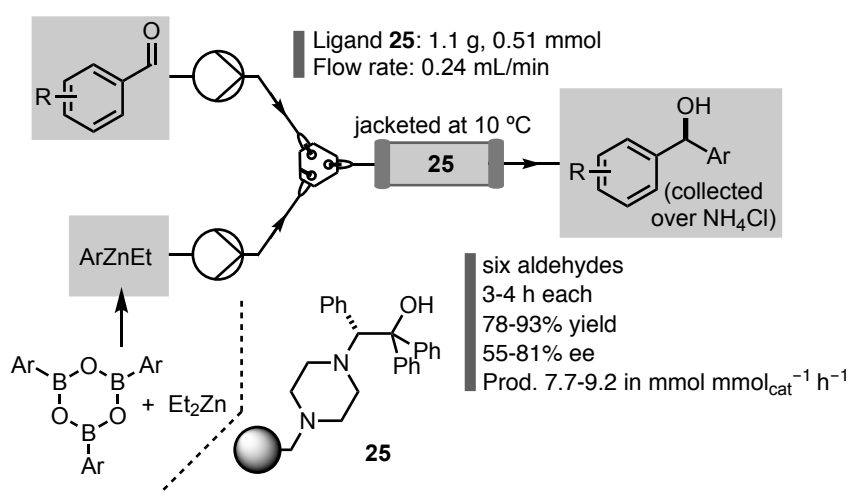

Figure 24. Aldehyde arylation in flow.

Despite the good results shown recorded, 25 proved to be unsuitable for long-term operation due to a fragmentation that took place in the presence of strong base (Scheme 1). After making the hypothesis that the presence of an aromatic group could stabilize the developing negative charge, we designed a supported amino alcohol that would disfavor this $\mathrm{C}-\mathrm{C}$ bond cleavage.

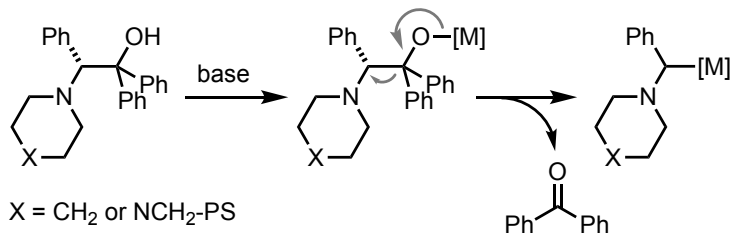

Scheme 1. Fragmentation of triphenylethylene oxide-derived amino alcohols.

Thus, 26 was prepared as an immobilized analogue of $\mathrm{MIB},{ }^{[96]}$ proving to be very active and recyclable, provided that oxygen was completely excluded from the system. The robustness of catalyst $\mathbf{2 6}$ was confirmed by a related flow process that was running for as long as $30 \mathrm{~h}$. Only a slight decrease in conversion was observed and the accumulated TON reached $251^{[97]}$ (Figure 25).

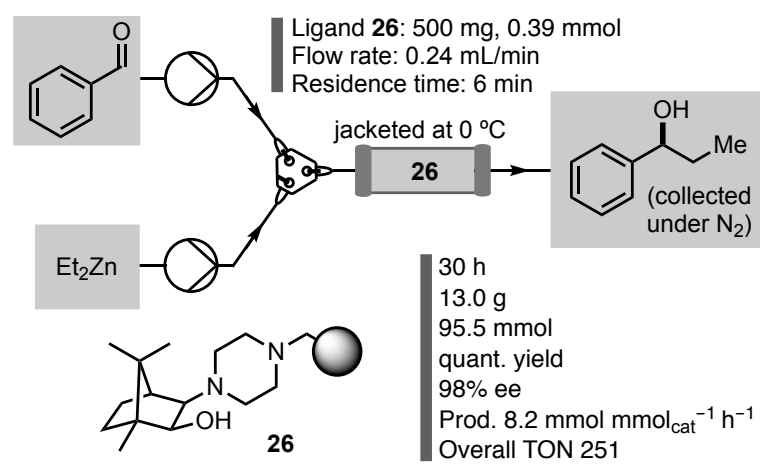

Figure 25. Aldehyde ethylation in flow with a supported piperazinoisoborneol ligand.

\subsection{A Phosphinooxazoline Ligand}

The Tsuji-Trost reaction, which involves the activation of allylic substrates with palladium complexes, followed by the interception of the resulting $\pi$-allyl intermediates with a suitable nucleophile, is a common strategy in organic synthesis. ${ }^{[98]}$ Several ligands have been developed to control the enantioselectivity of the process, and bidentate phosphinooxazolines (PHOX) are amongst the most successful. After optimizing the ligand structure, the anchoring strategy via CuAAc and the length of the linker, the flow experiment depicted in Figure 26 was carried out with 27. ${ }^{\text {[9] }}$ Based on the observation made in batch that use of low-power microwave irradiation significantly improved the results, the whole set-up was assembled without metallic pieces and placed inside the MW cavity in open-vessel mode. Thus, working at $0.12 \mathrm{~mL}$ $\mathrm{min}^{-1}$, the system was running for $3 \mathrm{~h}$, in which the conversion decreased from the initial $85 \%$ to $54 \%$, probably pointing out to palladium leaching. ${ }^{[100]}$ 


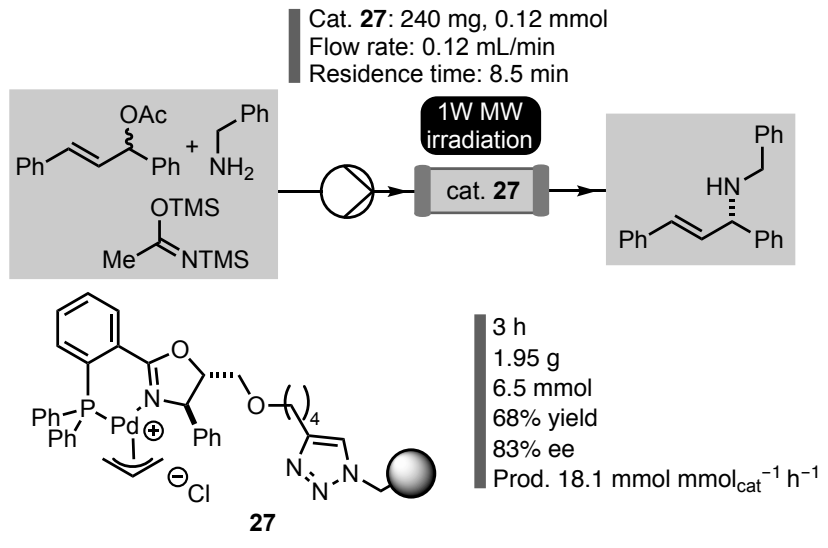

Figure 26. Continuous flow asymmetric allylic amination.

\subsection{A tris-Triazolyl Ligand for Copper}

In contrast to all the examples described above, the last project to be discussed does not deal with enantioselective catalysis. The ligand used in this case, the tris-triazolylmethanol[101] (TTM), was designed in our laboratories for the CuAAC, a reaction that in turn was crucial in its preparation. Despite the previous instances where this ligand had been immobilized, ${ }^{[101 b]}$ high levels of copper leaching had precluded implementation of flow processes. We reasoned that, if the complex was formed from a cationic coper species rather than with $\mathrm{CuCl}$, the chances of leaching would diminish. Consequently, solid-supported TTM was treated with $\left[\mathrm{Cu}(\mathrm{MeCN})_{4}\right] \mathrm{PF}_{6}$ and the resulting cationic complex 28 was benchmarked with the ethyl diazoacetate insertion onto ethanol, in the framework of a collaboration with the group of Díaz-Requejo and Pérez from the University of Huelva. ${ }^{[102]}$ The system was incredibly robust, allowing for a flow process that spanned $48 \mathrm{~h}$ working at flow rates as high as $500 \mu \mathrm{L} \mathrm{min}{ }^{-1}$. The only issue was that the resin had to be re-swollen every few hours due to the presence of ethanol, but $90 \%$ yield was still obtained, and the TON for this experiment alone reached an amazing 820 (Figure 27).

After this result, the same packed bed reactor with $\mathbf{2 8}$ was applied to an array of substrates including THF, cyclohexane or aniline, which furnished the $\mathrm{C}-\mathrm{H}$ and $\mathrm{N}-\mathrm{H}$ insertion products, and an alkyne, that gave rise to the cyclopropene. Overall, an accumulated TON of 915 was recorded, thanks to the stability of the cationic complex and the fast flow rates employed $(500 \mu \mathrm{L}$ $\mathrm{min}^{-1}$ ), which entailed a residence time as short as $1 \mathrm{~min}$.

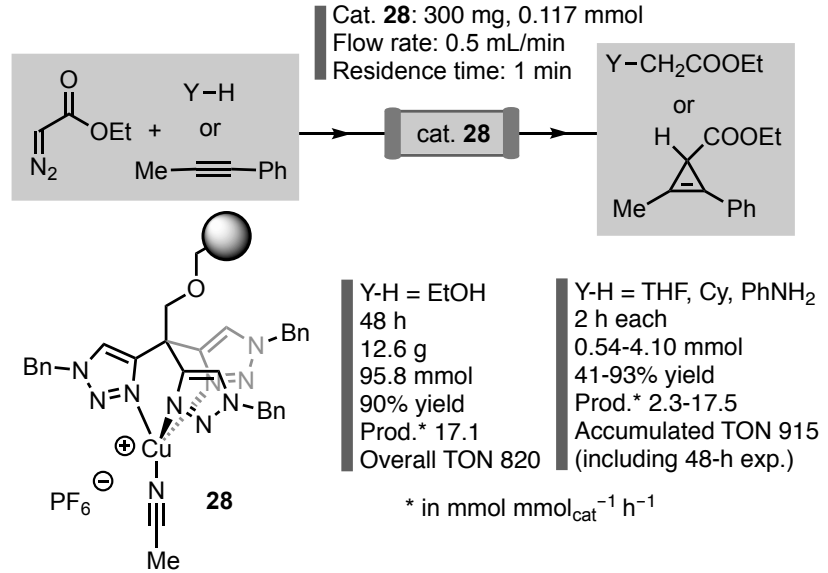

Figure 27. Cationic copper complex for the ethyl diazoacetate insertion in flow.

\subsection{Flow processes with metal organic frameworks (MOFs)}

In a fruitful collaboration with Prof. Belén Martin-Matute (Stockholm University) we have demonstrated that $\mathrm{Pd}$ nanoparticles supported on functionalized mesoporous MOFs can also be used in flow. To this end, the broad-scope SuzukiMiyaura synthesis of highly functionalized biaryls and the aerobic oxidation of alcohols were studied. ${ }^{[103]}$ These are, however, nonenantioselective applications involving achiral catalysts and will not be discussed in detail here.

\section{Summary and Outlook}

The implementation of continuous flow processes based on solidsupported chiral catalysts is a key enabling technology for the green production of enantiopure compounds. Catalyst design is critical to obtain a material that is robust under the reaction conditions, while allowing for high activities required for a singlepass operation. In this sense, the CuAAC-mediated installation of a triazole linker has proven a versatile approach, but the anchoring strategy will be eventually dictated by the reagents, solvent or even by-products that come in close contact with the catalytically active species. If the right buttons are pressed, one can generate a packed bed reactor that, much like a HPLC column, can be stored and used at the user's convenience.

The lessons learnt from the examples described herein (as well as many others described in the literature) are certain to improve the next generation of immobilized chiral catalysts, leading to a new scenario where flow chemistry becomes an alternative to batch processes thanks to the associated benefits in terms of process intensification. In the current scenario, sustainability issues are critical to decide the processes to be deployed in an industrial environment. Hence, we should not be surprised to see flow processes being adopted for the production of (enantiopure) fine chemicals, as they have been in the petrochemical and bulk chemicals industry. 


\section{Acknowledgements}

We would like to thank all the members of the Pericàs Lab at ICIQ who, with their dedication and effort, have made possible the research described herein. Their names appear in the corresponding references, and they deserve full credit for the work. Financial support from CERCA Programme/Generalitat de Catalunya, MINECO (CTQ2015-69136-R, AEI/MINECO/FEDER, UE and Severo Ochoa Excellence Accreditation 2014-2018, SEV-2013-0319) and DEC Generalitat de Catalunya (Grant 2014SGR827) is gratefully acknowledged.

Keywords: flow chemistry $\bullet$ immobilized catalysts $\cdot$ solidsupported catalysts $\bullet$ asymmetric catalysis $\bullet$ organocatalysis

[1] For a recent essay on sustainable chemistry, see: K. Kümmerer, Angew. Chem. Int. Ed. 2017, 56, 16420-16421.

[2] (a) P. T. Anastas, J. C. Warner, Green Chemistry: Theory and Practice, Oxford University Press, 2000; (b) P. Anastas, N. Eghbali, Chem. Soc Rev. 2010, 39, 301-312.

[3] (a) L. A. Nguyen, H. He, C. Pham-Huy, Int. J. Biomed. Sci. 2006, 2, 85100; (b) M. C. Nunez, M. E. Garcia-Rubino, A. Conejo-Garcia, O. CruzLopez, M. Kimatrai, M. A. Gallo, A. Espinosa, J. M. Campos, Curr. Med. Chem. 2009, 16, 2064-2074.

[4] E. N. Jacobsen, A. Pfaltz, H. Yamamoto, Comprehensive Asymmetric Catalysis. Supplement, Springer, Berlin; New York, 2004.

[5] For reviews on chiral catalyst immobilization, see: (a) D. E. De Vos, I. F. J. Vankelecom, P. A. Jacobs, Chiral Catalyst Immobilization and Recycling, Wiley-VCH, Weinheim ; New York, 2000; (b) M. Benaglia, A Puglisi, F. Cozzi, Chem. Rev. 2003, 103, 3401-3430; (c) M. Benaglia, New J. Chem. 2006, 30, 1525-1533; (d) F. Cozzi, Adv. Synth. Catal. 2006, 348, 1367-1390; (e) M. Gruttadauria, F. Giacalone, R. Noto, Chem. Soc. Rev. 2008, 37, 1666-1688; (f) E. L. Margelefsky, R. K. Zeidan, M. E. Davis, Chem. Soc. Rev. 2008, 37, 1118-1126; (g) M. Benaglia, Recoverable and Recyclable Catalysts, 1st ed., Wiley, Hoboken, N.J., 2009; (h) A. F. Trindade, P. M. P. Gois, C. A. M. Afonso, Chem. Rev. 2009, 109, 418-514; (i) T. E. Kristensen, T. Hansen, Eur. J. Org. Chem. 2010, 3179-3204.

[6] (a) A. Kirschning, W. Solodenko, K. Mennecke, Chem. Eur. J. 2006, 12 5972-5990; (b) X. Y. Mak, P. Laurino, P. H. Seeberger, Beilstein J. Org Chem. 2009, 5, 19; (c) A. Puglisi, M. Benaglia, V. Chiroli, Green Chem. 2013, 15, 1790-1813; (d) T. Tsubogo, T. Ishiwata, S. Kobayashi, Angew. Chem. Int. Ed. 2013, 52, 6590-6604; (e) D. Zhao, K. Ding, ACS Catal. 2013, 3, 928-944; (f) I. Atodiresei, C. Vila, M. Rueping, ACS Catal. 2015 1972-1985; (g) R. Munirathinam, J. Huskens, W. Verboom, Adv. Synth. Catal. 2015, 357, 1093-1123; (h) A. Puglisi, M. Benaglia, R. Porta, F. Coccia, Curr. Organocatal. 2015, 2, 79-101; (i) C. Rodríguez-Escrich, M. A. Pericàs, Eur. J. Org. Chem. 2015, 1173-1188; for recent examples of flow chemistry for the synthesis of pharmaceutical products, see: (j) B. Gutmann, D. Cantillo, C. O. Kappe, Angew. Chem. Int. Ed. 2015, 54, 6688-6728; (k) R. Porta, M. Benaglia, A. Puglisi, Org. Process Res. Dev. 2016, 20, 2-25.

[7] V. Hessel, Chem. Eng. Technol. 2009, 32, 1655-1681.

[8] US Government Accountability Office, GAO-18-307, February 2018.

[9] (a) V. V. Rostovtsev, L. G. Green, V. V. Fokin, K. B. Sharpless, Angew. Chem. Int. Ed. 2002, 41, 2596-2599; (b) C. W. Tornøe, C. Christensen, M. Meldal, J. Org. Chem. 2002, 67, 3057-3064; (c) M. Meldal, C. W. Tornøe, Chem. Rev. 2008, 108, 2952-3015.

[10] For a review on CuAAC to immobilize homogeneous catalysts, see: A. E. Fernandes, A. M. Jonas, O. Riant, Tetrahedron 2014, 70, 1709-1731.

[11] (a) R. B. Merrifield, J. Am. Chem. Soc. 1963, 85, 2149-2154; (b) R. B. Merrifield, Angew. Chem. Int. Ed. 1985, 24, 799-810.

[12] K. Kamahori, K. Ito, S. Itsuno, J. Org. Chem. 1996, 61, 8321-8324.
[13] (a) A. M. Hafez, A. E. Taggi, H. Wack, W. J. Drury, T. Lectka, Org. Lett. 2000, 2, 3963-3965; (b) A. M. Hafez, A. E. Taggi, T. Dudding, T. Lectka, J. Am. Chem. Soc. 2001, 123, 10853-10859; (c) A. M. Hafez, A. E. Taggi, T. Lectka, Chem. Eur. J. 2002, 8, 4114-4119; (d) D. Bernstein, S. France, J. Wolfer, T. Lectka, Tetrahedron: Asymmetry 2005, 16, 3481-3483; (e) S. France, D. Bernstein, A. Weatherwax, T. Lectka, Org. Lett. 2005, 7, 3009-3012.

[14] B. List, R. A. Lerner, C. F. Barbas, J. Am. Chem. Soc. 2000, 122, $2395-$ 2396.

[15] K. A. Ahrendt, C. J. Borths, D. W. C. MacMillan, J. Am. Chem. Soc. 2000, 122, 4243-4244.

[16] (a) P. Melchiorre, M. Marigo, A. Carlone, G. Bartoli, Angew. Chem. Int. Ed. 2008, 47, 6138-6171; (b) S. Bertelsen, K. A. Jørgensen, Chem. Soc. Rev. 2009, 38, 2178-2189.

[17] For a provocative, somehow biased assay on the viability of immobilized transition metal complexes as industrial catalysts, see: S. Hübner, J. G. de Vries, V. Farina, Adv. Synth. Catal. 2016, 358, 3-25.

[18] For selected references, see: (a) V. Chiroli, M. Benaglia, F. Cozzi, A. Puglisi, R. Annunziata, G. Celentano, Org. Lett. 2013, 15, 3590-3593; (b) V. Chiroli, M. Benaglia, A. Puglisi, R. Porta, R. P. Jumde, A. Mandoli, Green Chem. 2014, 16, 2798-2806; (c) R. Porta, M. Benaglia, A. Puglisi, A. Mandoli, A. Gualandi, P. G. Cozzi, ChemSusChem 2014, 7, 35343540; (d) R. Porta, M. Benaglia, F. Coccia, F. Cozzi, A. Puglisi, Adv. Synth. Catal. 2015, 357, 377-383; (e) R. Porta, M. Benaglia, R. Annunziata, A. Puglisi, G. Celentano, Adv. Synth. Catal. 2017, 359, 2375-2382.

[19] For selected references, see: (a) O. Bortolini, L. Caciolli, A. Cavazzini, V. Costa, R. Greco, A. Massi, L. Pasti, Green Chem. 2012, 14, 992-1000; (b) O. Bortolini, A. Cavazzini, P. P. Giovannini, R. Greco, N. Marchetti, A. Massi, L. Pasti, Chem. Eur. J. 2013, 19, 7802-7808; (c) D. Ragno, G. Di Carmine, A. Brandolese, O. Bortolini, P. P. Giovannini, A. Massi, ACS Catal. 2017, 7, 6365-6375.

[20] For selected references, see: (a) S. B. Ötvös, I. M. Mándity, F. Fülöp, J. Catal. 2012, 295, 179-185; (b) S. B. Ötvös, I. M. Mándity, F. Fülöp, ChemSusChem 2012, 5, 266-269.

[21] For selected references, see: G. Kardos, T. Soós, Eur. J. Org. Chem. 2013, 4490-4494.

[22] Y. Arakawa, H. Wennemers, ChemSusChem 2013, 6, 242-245.

[23] For a field guide to flow chemistry, see: M. B. Plutschack, B. Pieber, K. Gilmore, P. H. Seeberger, Chem. Rev. 2017, 117, 11796-11893.

[24] (a) S. Bahmanyar, K. N. Houk, H. J. Martin, B. List, J. Am. Chem. Soc. 2003, 125, 2475-2479; (b) A. Armstrong, R. A. Boto, P. Dingwall, J. Contreras-Garcia, M. J. Harvey, N. J. Mason, H. S. Rzepa, Chem. Sci. 2014, 5, 2057-2071.

[25] (a) A. Vidal-Ferran, N. Bampos, A. Moyano, M. A. Pericàs, A. Riera, J. K. M. Sanders, J. Org. Chem. 1998, 63, 6309-6318; (b) J. M. Fraile, J. A. Mayoral, J. Serrano, M. A. Pericàs, L. Solà, D. Castellnou, Org. Lett. 2003, 5, 4333-4335; (c) M. A. Pericàs, D. Castellnou, I. Rodríguez, A. Riera, L. Solà, Adv. Synth. Catal. 2003, 345, 1305-1313; (d) D. Castellnou, L. Solà, C. Jimeno, J. M. Fraile, J. A. Mayoral, A. Riera, M. A. Pericàs, J. Org. Chem. 2005, 70, 433-438.

[26] (a) D. Font, C. Jimeno, M. A. Pericàs, Org. Lett. 2006, 8, 4653-4655; (b) D. Font, S. Sayalero, A. Bastero, C. Jimeno, M. A. Pericàs, Org. Lett. 2008, 10, 337-340.

[27] E. Alza, C. Rodríguez-Escrich, S. Sayalero, A. Bastero, M. A. Pericàs, Chem. Eur. J. 2009, 15, 10167-10172.

[28] A. Odedra, P. H. Seeberger, Angew. Chem. Int. Ed. 2009, 48, 2699-2702.

[29] (a) S. P. Brown, M. P. Brochu, C. J. Sinz, D. W. C. MacMillan, J. Am. Chem. Soc. 2003, 125, 10808-10809; (b) Y. Hayashi, J. Yamaguchi, K. Hibino, M. Shoji, Tetrahedron Lett. 2003, 44, 8293-8296; (c) G. Zhong, Angew. Chem. Int. Ed. 2003, 42, 4247-4250.

[30] D. Font, A. Bastero, S. Sayalero, C. Jimeno, M. A. Pericàs, Org. Lett. 2007, 9, 1943-1946.

[31] X. C. Cambeiro, R. Martín-Rapún, P. O. Miranda, S. Sayalero, E. Alza, P. Llanes, M. A. Pericàs, Beilstein J. Org. Chem. 2011, 7, 1486-1493. 
[32] E. Alza, C. Rodríguez-Escrich, S. Sayalero, A. Bastero, M. A. Pericàs Chem. Eur. J. 2009, 15, 10167-10172.

[33] N. Zotova, A. Franzke, A. Armstrong, D. G. Blackmond, J. Am. Chem. Soc. 2007, 129, 15100-15101.

[34] C. Ayats, A. H. Henseler, M. A. Pericàs, ChemSusChem 2012, 5, 320325.

[35] (a) A. Mielgo, C. Palomo, Chem. Asian J. 2008, 3, 922-948; (b) K. L. Jensen, G. Dickmeiss, H. Jiang, Ł. Albrecht, K. A. Jørgensen, Acc. Chem. Res. 2011, 45, 248-264; (c) B. S. Donslund, T. K. Johansen, P. H. Poulsen, K. S. Halskov, K. A. Jørgensen, Angew. Chem. Int. Ed. 2015 54, 13860-13874.

[36] (a) J. Franzén, M. Marigo, D. Fielenbach, T. C. Wabnitz, A. Kjærsgaard K. A. Jørgensen, J. Am. Chem. Soc. 2005, 127, 18296-18304; (b) M. Marigo, T. C. Wabnitz, D. Fielenbach, K. A. Jørgensen, Angew. Chem. Int. Ed. 2005, 44, 794-797.

[37] Y. Hayashi, H. Gotoh, T. Hayashi, M. Shoji, Angew. Chem. Int. Ed. 2005 $44,4212-4215$.

[38] (a) H.-C. Guo, J.-A. Ma, Angew. Chem. Int. Ed. 2006, 45, 354-366; (b) C M. Volla, I. Atodiresei, M. Rueping, Chem. Rev. 2014, 114, 2390-2431.

[39] (a) E. Alza, M. A. Pericàs, Adv. Synth. Catal. 2009, 351, 3051-3056; (b) E. Alza, S. Sayalero, P. Kasaplar, D. Almaşi, M. A. Pericàs, Chem. Eur. J. 2011, 17, 11585-11595.

[40] Y. Hayashi, M. Toyoshima, H. Gotoh, H. Ishikawa, Org. Lett. 2009, 11, 45-48.

[41] E. Alza, S. Sayalero, X. Cambeiro, R. Martín-Rapún, P. Miranda, M. A. Pericàs, Synlett 2011, 464-468.

[42] For a practical solution to this problem, see: K. Gilmore, D. Kopetzki, J. W. Lee, Z. Horvath, D. T. McQuade, A. Seidel-Morgenstern, P. H. Seeberger, Chem. Commun. 2014, 50, 12652-12655.

[43] Y. Hayashi, D. Okamura, T. Yamazaki, Y. Ameda, H. Gotoh, S. Tsuzuki, T. Uchimaru, D. Seebach, Chem. Eur. J. 2014, 20, 17077-17088.

[44] (a) A. Bøgevig, K. Juhl, N. Kumaragurubaran, W. Zhuang, K. A Jørgensen, Angew. Chem. Int. Ed. 2002, 41, 1790-1793; (b) B. List, J. Am. Chem. Soc. 2002, 124, 5656-5657.

[45] X. Fan, S. Sayalero, M. A. Pericàs, Adv. Synth. Catal. 2012, 354, 2971 2976

[46] (a) C. Sparr, W. B. Schweizer, H. M. Senn, R. Gilmour, Angew. Chem. Int. Ed. 2009, 48, 3065-3068; (b) C. Sparr, E.-M. Tanzer, J. Bachmann, R. Gilmour, Synthesis 2010, 1394-1397; (c) E.-M. Tanzer, L. E. Zimmer, W. B. Schweizer, R. Gilmour, Chem. Eur. J. 2012, 18, 11334-11342; (d) I. G. Molnár, E.-M. Tanzer, C. Daniliuc, R. Gilmour, Chem. Eur. J. 2014 20, 794-800.

[47] I. Sagamanova, C. Rodríguez-Escrich, I. G. Molnár, S. Sayalero, R Gilmour, M. A. Pericàs, ACS Catal. 2015, 5, 6241-6248.

[48] H. Xie, L. Zu, H. Li, J. Wang, W. Wang, J. Am. Chem. Soc. 2007, 129, 10886-10894.

[49] P. Llanes, C. Rodríguez-Escrich, S. Sayalero, M. A. Pericàs, Org. Lett. 2016, 18, 6292-6295.

[50] R. Martín-Rapún, X. Fan, S. Sayalero, M. Bahramnejad, F. Cuevas, M. A. Pericàs, Chem. Eur. J. 2011, 17, 8780-8783.

[51] R. Martín-Rapún, S. Sayalero, M. A. Pericàs, Green Chem. 2013, 15, 3295-3301.

[52] For a review on primary amine organocatalysts, see: L.-W. Xu, J. Luo, Y Lu, Chem. Commun. 2009, 1807-1821.

[53] C. Ayats, A. H. Henseler, E. Dibello, M. A. Pericàs, ACS Catal. 2014, 4, 3027-3033.

[54] For a review on Cinchona-based primary amine organocatalysts, see: $P$. Melchiorre, Angew. Chem. Int. Ed. 2012, 51, 9748-9770.

[55] J. Izquierdo, C. Ayats, A. H. Henseler, M. A. Pericàs, Org. Biomol. Chem 2015, 13, 4204-4209.

[56] (a) C. Liu, Y. Lu, Org. Lett. 2010, 12, 2278-2281; (b) H. W. Moon, D. Y. Kim, Tetrahedron Lett. 2010, 51, 2906-2908.

[57] (a) W. S. Rapson, R. Robinson, J. Chem. Soc. 1935, 1935, 1285-1288; (b) E. J. Corey, M. Ohno, R. B. Mitra, P. A. Vatakencherry, J. Am. Chem. Soc. 1964, 86, 478-485.
[58] (a) Z. G. Hajos, D. R. Parrish, Vol. DE 2102623, 1971; (b) Z. G. Hajos, D. R. Parrish, J. Org. Chem. 1974, 39, 1615-1621; (c) R. A. Micheli, Z. G. Hajos, N. Cohen, D. R. Parrish, L. A. Portland, W. Sciamanna, M. A. Scott, P. A. Wehrli, J. Org. Chem. 1975, 40, 675-681; (d) S. Takano, C. Kasahara, K. Ogasawara, J. Chem. Soc., Chem. Commun. 1981, 1981, 635-637.

[59] (a) U. Eder, G. Sauer, R. Wiechert, Angew. Chem. Int. Ed. 1971, 10, 496497; (b) U. Eder, G. R. Sauer, R. Wiechert, Vol. DE 2014757, 1971; (c) J. Gutzwiller, P. Buchschacher, A. Früst, Synthesis 1977, 167-168.

[60] (a) P. Zhou, L. Zhang, S. Luo, J.-P. Cheng, J. Org. Chem. 2012, 77, 2526-2530; (b) C. Xu, L. Zhang, P. Zhou, S. Luo, J.-P. Cheng, Synthesis 2013, 45, 1939-1945.

[61] S. Cañellas, C. Ayats, A. H. Henseler, M. A. Pericàs, ACS Catal. 2017, 7, 1383-1391.

[62] (a) J. Alemán, A. Parra, H. Jiang, K. A. Jørgensen, Chem. Eur. J. 2011, 17, 6890-6899; (b) R. Ian Storer, C. Aciro, L. H. Jones, Chem. Soc. Rev. 2011, 40, 2330-2346; (c) M. Tsakos, C. G. Kokotos, Tetrahedron 2013, 69, 10199-10222; (d) P. Chauhan, S. Mahajan, U. Kaya, D. Hack, D. Enders, Adv. Synth. Catal. 2015, 357, 253-281.

[63] J. P. Malerich, K. Hagihara, V. H. Rawal, J. Am. Chem. Soc. 2008, 130, 14416-14417

[64] For reviews on solid-supported chiral Brønsted acids, see: (a) A. K. Mutyala, N. T. Patil, Org. Chem. Front. 2014, 1, 582-586; (b) C. Rodríguez-Escrich, Chim. Oggi 2015, 33, 12-15.

[65] P. Kasaplar, P. Riente, C. Hartmann, M. A. Pericàs, Adv. Synth. Catal. 2012, 354, 2905-2910.

[66] P. Kasaplar, C. Rodríguez-Escrich, M. A. Pericàs, Org. Lett. 2013, 15, 3498-3501.

[67] (a) D. K. Nair, R. F. S. Menna-Barreto, E. N. da Silva Junior, S. M. Mobin, I. N. N. Namboothiri, Chem. Commun. 2014, 50, 6973-6976; (b) G. A. M. Jardim, T. T. Guimaraes, M. d. C. F. R. Pinto, B. C. Cavalcanti, K. M. de Farias, C. Pessoa, C. C. Gatto, D. K. Nair, I. N. N. Namboothiri, E. N. da Silva Junior, MedChemComm 2015, 6, 120-130.

[68] L. Osorio-Planes, C. Rodríguez-Escrich, M. A. Pericàs, Catal. Sci. Technol. 2016, 6, 4686-4689.

[69] (a) M. S. Sigman, E. N. Jacobsen, J. Am. Chem. Soc. 1998, 120, 49014902; (b) M. S. Sigman, P. Vachal, E. N. Jacobsen, Angew. Chem. Int. Ed. 2000, 39, 1279-1281; (c) P. Vachal, E. N. Jacobsen, Org. Lett. 2000, 2, 867-870; (d) P. Vachal, E. N. Jacobsen, J. Am. Chem. Soc. 2002, 124, 10012-10014; (e) A. G. Wenzel, E. N. Jacobsen, J. Am. Chem. Soc. 2002, 124, 12964-12965.

[70] (a) T. Okino, Y. Hoashi, T. Furukawa, X. Xu, Y. Takemoto, J. Am. Chem. Soc. 2005, 127, 119-125; (b) Y. Takemoto, Org. Biomol. Chem. 2005, 3 , 4299-4306.

[71] P. Kasaplar, E. Ozkal, C. Rodríguez-Escrich, M. A. Pericàs, Green Chem. 2015, 17, 3122-3129.

[72] (a) X. Xu, T. Yabuta, P. Yuan, Y. Takemoto, Synlett 2006, 137-140; (b) S. H. Jung, D. Y. Kim, Tetrahedron Lett. 2008, 49, 5527-5530.

[73] T. Akiyama, J. Itoh, K. Yokota, K. Fuchibe, Angew. Chem. Int. Ed. 2004, 43, 1566-1568.

[74] D. Uraguchi, M. Terada, J. Am. Chem. Soc. 2004, 126, 5356-5357.

[75] (a) M. Terada, Chem. Commun. 2008, 4097-4112; (b) A. Zamfir, S. Schenker, M. Freund, S. B. Tsogoeva, Org. Biomol. Chem. 2010, 8, 5262-5276; (c) D. Parmar, E. Sugiono, S. Raja, M. Rueping, Chem. Rev. 2014, 114, 9047-9153.

[76] (a) M. Rueping, E. Sugiono, A. Steck, T. Theissmann, Adv. Synth. Catal. 2010, 352, 281-287; (b) C. Bleschke, J. Schmidt, D. S. Kundu, S. Blechert, A. Thomas, Adv. Synth. Catal. 2011, 353, 3101-3106; (c) D. S. Kundu, J. Schmidt, C. Bleschke, A. Thomas, S. Blechert, Angew. Chem. Int. Ed. 2012, 51, 5456-5459.

[77] L. Osorio-Planes, C. Rodríguez-Escrich, M. A. Pericàs, Chem. Eur. J. 2014, 20, 2367-2372.

[78] Q. Kang, Z.-A. Zhao, S.-L. You, J. Am. Chem. Soc. 2007, 129, 14841485.

[79] (a) S. Hoffmann, A. M. Seayad, B. List, Angew. Chem. Int. Ed. 2005, 44, 7424-7427; (b) G. Adair, S. Mukherjee, B. List, Aldrichimica Acta 2008, 
41, 31-39; (c) M. Klussmann, L. Ratjen, S. Hoffmann, V. Wakchaure, R. Goddard, B. List, Synlett 2010, 2189-2192.

[80] P. Jain, J. C. Antilla, J. Am. Chem. Soc. 2010, 132, 11884-11886.

[81] L. Clot-Almenara, C. Rodríguez-Escrich, L. Osorio-Planes, M. A. Pericàs, ACS Catal. 2016, 7647-7651.

[82] (a) D. M. Flanigan, F. Romanov-Michailidis, N. A. White, T. Rovis, Chem Rev. 2015; (b) R. S. Menon, A. T. Biju, V. Nair, Chem. Soc. Rev. 2015 (c) M. H. Wang, K. A. Scheidt, Angew. Chem. Int. Ed. 2016, 55, 1491214922.

[83] J. Merad, J.-M. Pons, O. Chuzel, C. Bressy, Eur. J. Org. Chem. 2016 5589-5610.

[84] (a) V. B. Birman, H. Jiang, X. Li, L. Guo, E. W. Uffman, J. Am. Chem Soc. 2006, 128, 6536-6537; (b) V. B. Birman, H. Jiang, X. Li, Org. Lett 2007, 9, 3237-3240; (c) V. D. Bumbu, V. B. Birman, J. Am. Chem. Soc. 2011, 133, 13902-13905; (d) X. Yang, V. D. Bumbu, P. Liu, X. Li, H. Jiang, E. W. Uffman, L. Guo, W. Zhang, X. Jiang, K. N. Houk, V. B. Birman, J. Am. Chem. Soc. 2012, 134, 17605-17612; (e) V. D. Bumbu, X. Yang, V. B. Birman, Org. Lett. 2013, 15, 2790-2793; (f) N. A. Ahlemeyer, V. B Birman, Org. Lett. 2016; (g) V. B. Birman, Aldrichimica Acta 2016, 49, 23-33.

[85] M. Kobayashi, S. Okamoto, Tetrahedron Lett. 2006, 47, 4347-4350.

[86] K. N. Van, L. C. Morrill, A. D. Smith, D. Romo, in Lewis Base Catalysis in Organic Synthesis, Wiley-VCH, Weinheim, Germany, 2016, pp. 527654.

[87] (a) D. Belmessieri, L. C. Morrill, C. Simal, A. M. Z. Slawin, A. D. Smith, J Am. Chem. Soc. 2011, 133, 2714-2720; (b) L. C. Morrill, T. Lebl, A. M. Z. Slawin, A. D. Smith, Chem. Sci. 2012, 3, 2088-2093; (c) C. Simal, T. Lebl, A. M. Z. Slawin, A. D. Smith, Angew. Chem. Int. Ed. 2012, 51, 36533657; (d) L. C. Morrill, J. Douglas, T. Lebl, A. M. Z. Slawin, D. J. Fox, A D. Smith, Chem. Sci. 2013, 4, 4146-4155; (e) E. R. T. Robinson, C Fallan, C. Simal, A. M. Z. Slawin, A. D. Smith, Chem. Sci. 2013, 4, 2193 2200; (f) S. R. Smith, S. M. Leckie, R. Holmes, J. Douglas, C. Fallan, P. Shapland, D. Pryde, A. M. Z. Slawin, A. D. Smith, Org. Lett. 2014, 16, 2506-2509; (g) S. R. Smith, C. Fallan, J. E. Taylor, R. McLennan, D. S. B. Daniels, L. C. Morrill, A. M. Z. Slawin, A. D. Smith, Chem. Eur. J. 2015 21, 10530-10536; (h) D. G. Stark, L. C. Morrill, D. B. Cordes, A. M. Z. Slawin, T. J. C. O'Riordan, A. D. Smith, Chem. Asian J. 2015, 11, 395400; (i) E. Robinson, D. M. Walden, C. Fallan, M. Greenhalgh, P. Ha Yeon Cheong, A. D. Smith, Chem. Sci. 2016; (j) C. M. Young, D. G. Stark T. H. West, J. E. Taylor, A. D. Smith, Angew. Chem. Int. Ed. 2016, 55, 14394-14399; (k) A. Matviitsuk, M. D. Greenhalgh, D.-J. B. Antúnez, A. M. Z. Slawin, A. D. Smith, Angew. Chem. Int. Ed. 2017, 56, 12282-12287.

[88] (a) V. C. Purohit, A. S. Matla, D. Romo, J. Am. Chem. Soc. 2008, 130 10478-10479; (b) C. A. Leverett, V. C. Purohit, D. Romo, Angew. Chem. Int. Ed. 2010, 49, 9479-9483; (c) C. A. Leverett, V. C. Purohit, A. G. Johnson, R. L. Davis, D. J. Tantillo, D. Romo, J. Am. Chem. Soc. 2012 ,
134, 13348-13356; (d) G. Liu, M. E. Shirley, K. N. Van, R. L. McFarlin, D. Romo, Nature Chem. 2013, 5, 1049.

[89] J. Izquierdo, M. A. Pericàs, ACS Catal. 2016, 6, 348-356.

[90] S. Wang, J. Izquierdo, C. Rodríguez-Escrich, M. A. Pericàs, ACS Catal. 2017, 7, 2780-2785.

[91] R. M. Neyyappadath, R. Chisholm, M. D. Greenhalgh, C. RodríguezEscrich, M. A. Pericàs, G. Hähner, A. D. Smith, ACS Catal. 2018, 8, 1067-1075.

[92] R. Noyori, M. Kitamura, Angew. Chem. Int. Ed. 1991, 30, 49-69.

[93] (a) L. Solà, K. S. Reddy, A. Vidal-Ferran, A. Moyano, M. A. Pericàs, A. Riera, A. Alvarez-Larena, J.-F. Piniella, J. Org. Chem. 1998, 63, 70787082; (b) K. S. Reddy, L. Solà, A. Moyano, M. A. Pericàs, A. Riera, J. Org. Chem. 1999, 64, 3969-3974; (c) N. García-Delgado, M. Fontes, M. A. Pericàs, A. Riera, X. Verdaguer, Tetrahedron: Asymmetry 2004, 15, 2085-2090; (d) N. García-Delgado, K. S. Reddy, L. Solà, A. Riera, M. A. Pericàs, X. Verdaguer, J. Org. Chem. 2005, 70, 7426-7428; (e) C. Jimeno, S. Sayalero, T. Fjermestad, G. Colet, F. Maseras, M. A. Pericàs, Angew. Chem. Int. Ed. 2008, 47, 1098-1101; (f) S. Rodríguez-Escrich, K. S. Reddy, C. Jimeno, G. Colet, C. Rodríguez-Escrich, L. Solà, A. VidalFerran, M. A. Pericàs, J. Org. Chem. 2008, 73, 5340-5353.

[94] M. A. Pericàs, C. I. Herrerías, L. Solà, Adv. Synth. Catal. 2008, 350, $927-$ 932.

[95] J. Rolland, X. C. Cambeiro, C. Rodríguez-Escrich, M. A. Pericàs, Beilstein J. Org. Chem. 2009, 5, 56.

[96] W. A. Nugent, Chem. Commun. 1999, 1369-1370.

[97] L. Osorio-Planes, C. Rodríguez-Escrich, M. A. Pericàs, Org. Lett. 2012, 14, 1816-1819.

[98] (a) B. M. Trost, M. L. Crawley, Chem. Rev. 2003, 103, 2921-2944; (b) Z. Lu, S. Ma, Angew. Chem. Int. Ed. 2008, 47, 258-297.

[99] D. Popa, R. Marcos, S. Sayalero, A. Vidal-Ferran, M. A. Pericàs, Adv. Synth. Catal. 2009, 351, 1539-1556.

[100] For a study on Pd leaching, see: R. Greco, W. Goessler, D. Cantillo, C. O. Kappe, ACS Catal. 2015, 1303-1312.

[101] (a) S. Özçubukçu, E. Ozkal, C. Jimeno, M. A. Pericàs, Org. Lett. 2009, 11, 4680-4683; (b) E. Ozkal, S. Özçubukçu, C. Jimeno, M. A. Pericàs, Catal. Sci. Technol. 2012, 2, 195-200; (c) E. Ozkal, P. Llanes, F. Bravo, A. Ferrali, M. A. Pericàs, Adv. Synth. Catal. 2014, 356, 857-869; (d) P. Etayo, C. Ayats, M. A. Pericàs, Chem. Commun. 2016, 52, 1997-2010.

[102] L. Maestre, E. Ozkal, C. Ayats, A. Beltrán, M. M. Díaz-Requejo, P. J. Pérez, M. A. Pericàs, Chem. Sci. 2015, 6, 1510-1515.

[103] (a) V. Pascanu, A. Bermejo Gómez, C. Ayats, A. E. Platero-Prats, F. Carson, J. Su, Q. Yao, M. À. Pericàs, X. Zou, B. Martín-Matute, ACS Catal. 2015, 5, 472-479; (b) V. Pascanu, P. R. Hansen, A. Bermejo Gómez, C. Ayats, A. E. Platero-Prats, M. J. Johansson, M. A. Pericàs, B. Martín-Matute, ChemSusChem 2015, 8, 123-130. 
Entry for the Table of Contents (Please choose one layout)

Layout 1:

\section{PERSONAL ACCOUNT}

The flexibility, reduced footprint and minimization of waste products associated with flow techniques constitutes a perfect match for solidsupported chiral catalysts. The efforts made in our group to identify ever more active, robust and selective heterogenized catalysts and the subsequent applications in asymmetric flow processes are summarized here.

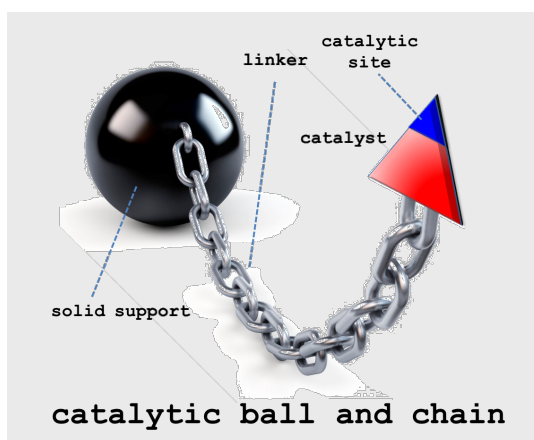

Carles Rodríguez-Escrich* and Miquel A. Pericàs*

Page No. - Page No.

Title 